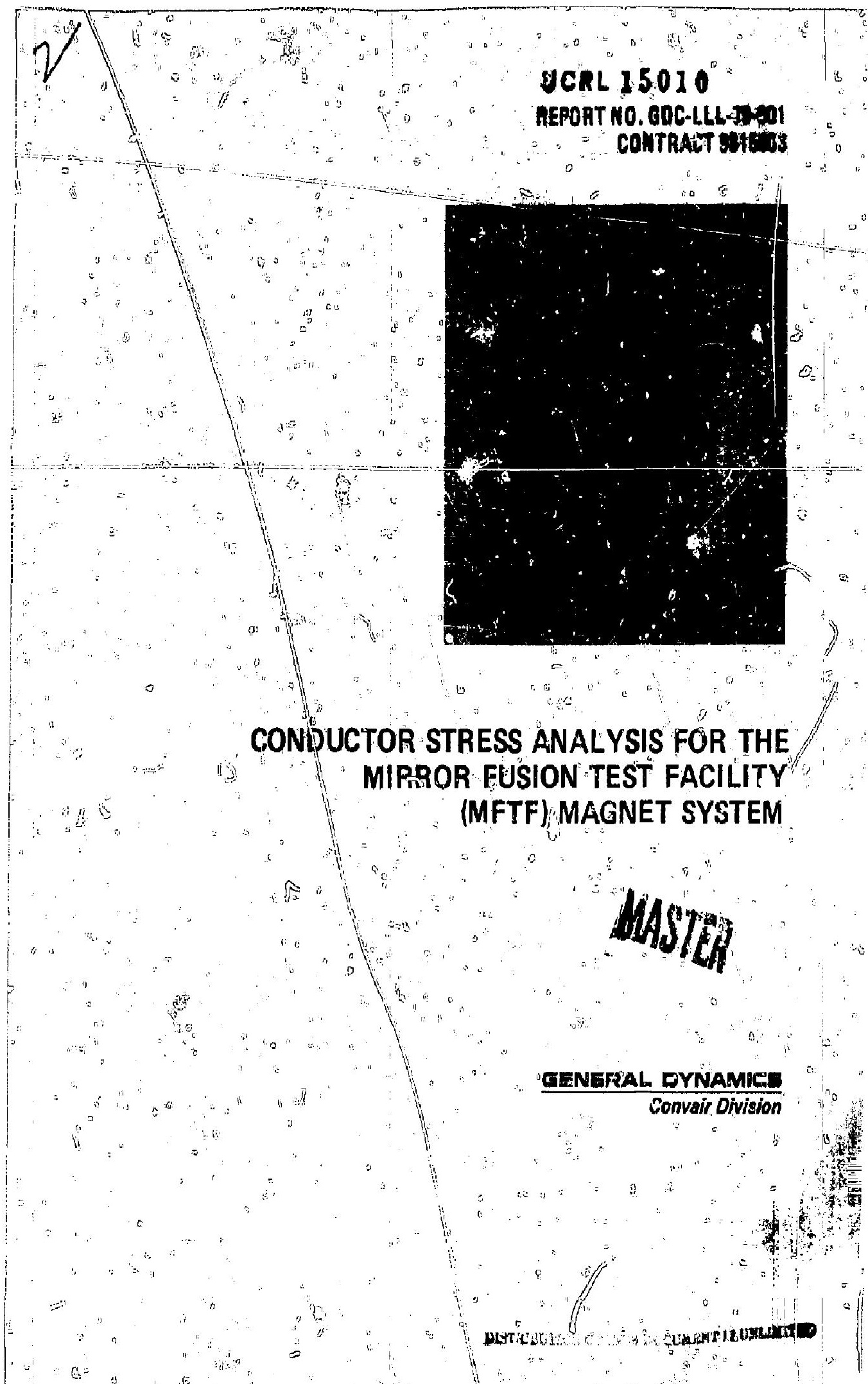




\section{CONDUCTOR STRESS ANALYSIS FOR THE MIRROR FUSION TEST FACIEITY (MFTF) MAGNET SYSTEM}

March 1979

R.W. 8aldi

C. D. Poniktera

Preparad Under

Contract 9815603

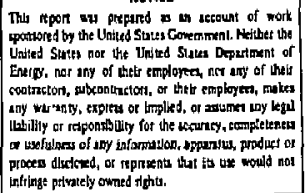

Prepared for

UNIVERSITY OF CALIFORNIA

LAWRENCE UIVERMORE LABORATORY

P.0. Box 5012 (L-446)

Livermore, California 94550

Prepared by

GENERAL DYNAMICS CONVAIA DIVISION

P.O. Box 80847

San Diego, Califomia 92138 
THIS DOCUMENT PREPARED BY GENERAL DYNAMICS/CONVAIR AND APPROVED BY

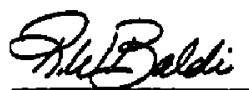

R. W. BALDI

CHIEF ENGINEER

MFTF MAGNET SYSTEM

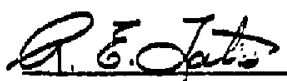

R. E. TATRÓ

PROGRAM MANAGER

MFTF MAGNET SYSTEM 
TABLE OF CONTENTS

Section

Page

1 INTRODUCTION 1

2 STRUCTURAL REQUIREMENTS 3

2.1 MATERLAL PROPERTIES 3

2.2 FACTORS OF SAFETY 3

3 ANALYSIS 6

3.1 INTRODUCTION 6

3.2 BASELINE 6

$3.30 .005^{\prime \prime}$ GAP HOMOGENIZATION

$3.40 .010^{\prime \prime}$ GAP HOMOGENIZATION 25

$4 \quad$ RESULTS $\quad 27$

4.1 GENERAL 27

4.2 BASELINE NO. 6

$4.30 .005^{\prime \prime}$ GAP HOMOGENIZATION

$4.40 .010^{\prime \prime}$ GAP HOMOGENLATION 32

4.5 PARAMETRIC COMPARISON 32

5 CONCLUSIONS

6 RECONMENDATIONS

7 REFERENCES 41

APPENDIX A: MFTF CONDUCTOR PACK ANALYSIS: BASELINE A-1 MODEL GDSAP COMPUTER ANALYSIS RESULTS

APPENDIX B: MFTF CONDUCTOR PACK ANALYSTS: 0.005" B-1 WINDING GAP GDSAP COMPUTER ANALYSIS RESULTS

APPENDIX C: MFTF CONDUCTOR PACK ANALYSIS: $0.010^{\prime \prime} \quad C-1$ WINDING GAP GDSAP COMPUTER ANALYSIS RESULTS 
LIST OF FIGURES

Figure

$\underline{\text { Page }}$

1.1 GDSAP MFTF Finite Element Model 2

3.1 MFTF Conductor/Insulation Cross-Section 7

3.2 MFTF Insulation Buttong 8

3.3 MFTF Slotted Insulation 9

3.4 MFTF Superconductor Copper Wrap 10

3.5 Orientation Diagram for Connectivity Schematles 11

3.6 MFTF Conductor Pack Connectivity Scheme No. 1

3.7 MFTF Conductor Pack Connectivity Scheme No. 1 F.E. Model Hoop Stresses 14

3.8 MFTF Conductor Pack Connectivity Scheme No. $2 \quad 16$

3.9 MFTF Conductor Pack Connectivity scheme No. 1 and No. 2 F.E. Model Hoop Stress Comparison $\quad 17$

3.10 MFTF Conductor Pack Connectivity Scheme No. 3

3.11 MFTF Conductor Pack Connectivity Scheme No. $4 \quad 19$

3.12 MFTF Conductor Pack Connectivity Scheme No. 5

3.13 MFTF Conductor Pack Connectivity Scheme No. 3 F. E. Model Hoop Stresses $\quad 21$

3.14 MFTF Conductor Pack Connectivity Scheme No. 4 F. E. Model Hoop Stresses

3.15 MFTF Conductor Pack Connectivity Scheme No. 5 F. E. Model Hoop Stresses 23

3. 16 MFTF Conductor Pack Connectivity Scheme No. 6

4.1 MFTF Conductor Pack Connectivity Scheme No. 6 F. E. Model Hoop Stresses 29

4.2 Baseline No. 6 - Conductor Hoop Stress Curve Fit Results 30

4.3 MFTF Conductor Fack Hoop Stress Extrapolation Scheme 31

4.4 MFTF Conductor Pack Connectivity Scheme No. 6 for 0.005 Inch Winding Gap Homogenization 


\section{LIST OF FIGLRES (Continued)}

Figure

4.5 MFTF Conductor Pack Connectivity Scheme No. 6

F. E. Model Hoop Stresses for 0.005 Inch Winding Gap Homogenization

4. 6 MFTF Conductor Pack Connectivity Scheme No. 6 for 0.010 inch Winzing Gap Homogenization

4.7 MFTF Conductor Pack Connectivity Scheme No. 6 F. E, Model Hoop Stresses for 0.010 Inch Winding Gap Homogenization

\section{LIST OF TABLES}

$\underline{\text { Table }}$

Page

2.1 Structural Material Mechanical Properties 4

2.2 Magnet Structural Safety Factors 5

4.1 Conductor Pack Connectivity Study Results Summary 28

4. 2 Conductor Pack Winding Gap Homogenization Study Results Comparison 


\section{SUMMARY}

This report describes the analysis performed to estrblish the sensitivity of winding gaps on conductor hoop stress. Since this task was a follow-on to the program that confirmed the structural integrity of the MFTF magnet case, jacket, and shield system (Ref. 1), every effort was made to utilize analysis methods and tools developed during that program. Figure 1.1 illustrates the large, 5000 degree of freedom GDSAP model developed during that program which was used extensively throughout this analysis task. 'This model accurately represents the case and jacket structure and simulates the conductor pack stiffness with an array of interconnected rod elements. All results contained herein are based on linear-elastlc, small deflection theory.

To enable us to use this analysis tool, homogenization techniques were utilized to idealize the non-linear gap problem into a linear problem compatible with our existing analysis technigues. Details of the homogenization are presented in Section 3, Analysis.

This study has shown that conductor hoop stresses are not particularly sensitive to the winding gaps analyzed $(0.005$ and $0.010 \mathrm{inch})$, but it is still recommended that winding gaps be kept minimal because of conductor pack movement considerations. 


\section{INTRODUCTION}

This report documents the stress analysis of the MFTF magnet system conductor pack. The analysis is based on LLL criteria to establish the sensitivity of concuctor hoop stress to interconductor winding gaps of 0.005 and 0.010 inch. LLL defined the conductor pack material properties which were the basis for this analysis.

The finite element analysis that forms the basis of the work contained herein is summarized in Sections 3 and 4. Details of the finite eleinent model (Figure 1.1) may be found in Ref. 1, Appendix A, Volume I.

Detailed computer output and plate stress margin of safety summ iries for the baseline, $0.005 \mathrm{in}$. winding gap and $0.010 \mathrm{in}$. winding gap analyses are presented in Appendices A through $\mathrm{C}$, respectively. 


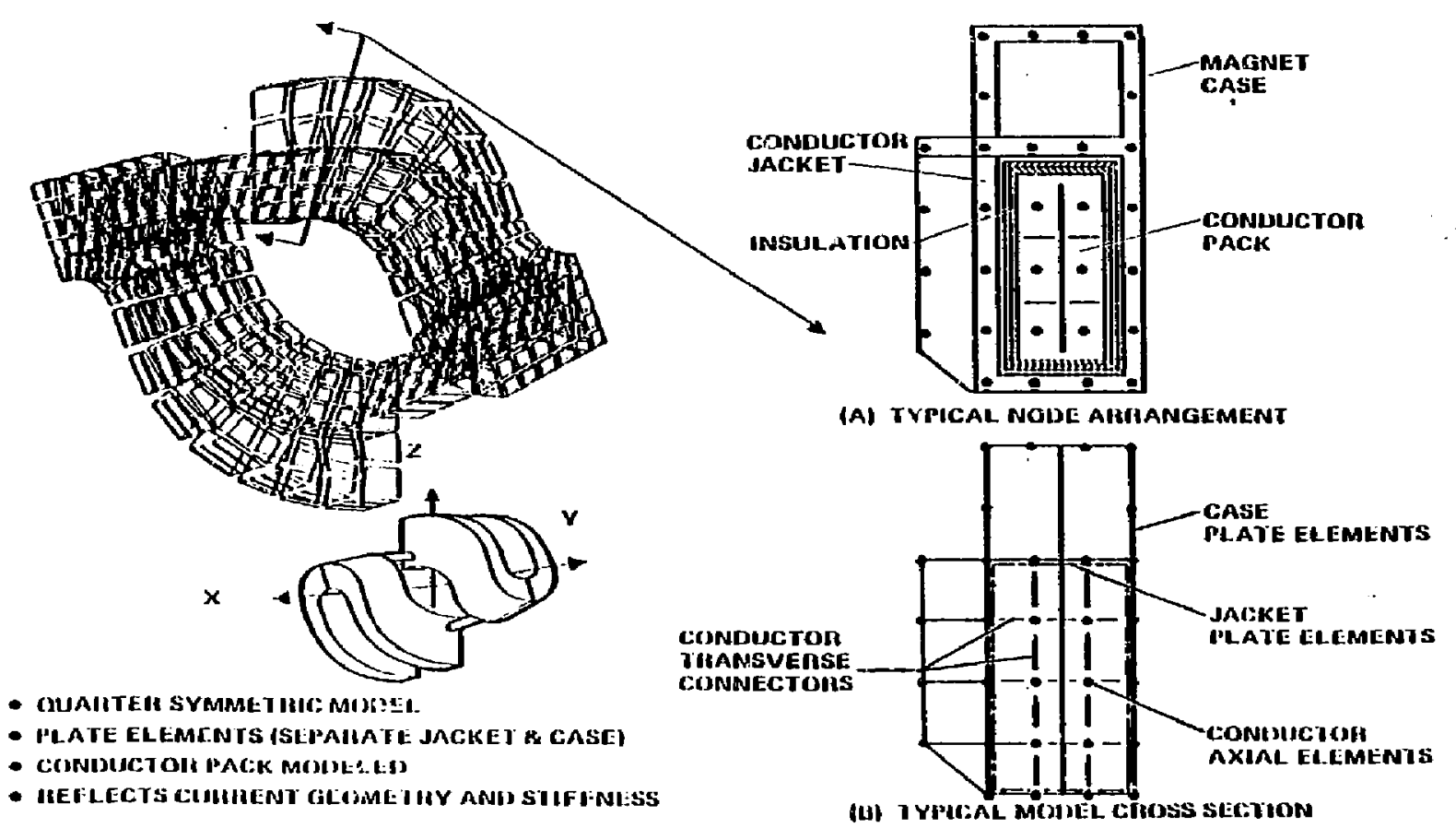

Figure 1.1. GDSAP MFTF Finite Element Model 


\section{STRUCTURAL REQULREMENTS}

\subsection{MATERLAL PROPERTIES}

The mechanical properties for the MFTF structural materials are listed in Table 2.1. The properties for the magnet case, intercoil, and jacket are the samo as those used in the previous MFTF structural analysis tasks (Ref. 1). The propertles tabulated for concuctor bundle stack were developed and obtained from LLL (Ref. 2).

\subsection{FACTORS OF S.AFETY}

Factors of safety used in this analysis are the same as those used in previous MFTF structural analysis tasks for the case, facket and intercoil structure (Ref. 1). At that time, LLI specified that the coil siructure shall have a minimum factor of safety of 1.5 on yield strength for operating magnetic and thermal loads. Factors of safety used on the MFTF structure are shown in Table 2.2. 
Table 2. 1. Structural Material Mechanical Properties

\begin{tabular}{|c|c|c|c|c|c|c|}
\hline Material & Usage & $\begin{array}{c}\text { Tenip } \\
{ }^{\circ} \mathbf{K} \\
\end{array}$ & $\begin{array}{l}F_{\mathrm{TU}} \\
\text { (kgi) }\end{array}$ & $\begin{array}{r}\text { F } \\
\text { TY } \\
\text { (kEI) }\end{array}$ & $\begin{array}{c}E \\
10^{6} \\
\text { (psi) }\end{array}$ & Sourco \\
\hline $304 \mathrm{~L}$ & support struts & $\begin{array}{l}\text { RT } \\
\text { 4. } 5\end{array}$ & $\begin{array}{l}100 \\
245\end{array}$ & $\begin{array}{l}40 \\
70\end{array}$ & $\begin{array}{l}28.5 \\
29.6\end{array}$ & LLL \\
\hline $\begin{array}{l}304 \mathrm{LN} \\
(0.12 \% \mathrm{~N})\end{array}$ & $\begin{array}{l}\text { Magnet Case and } \\
\text { Intercoil }\end{array}$ & 4.5 & 244.6 & 111. 8* & 29.7 & NBS \\
\hline E316L $\quad \begin{array}{l}\triangle F e=4.5 \\
\triangle F e=9.2\end{array}$ & Case Weld Metal & $\begin{array}{l}4.5 \\
4.5\end{array}$ & $\begin{array}{l}193 \\
187\end{array}$ & $\begin{array}{l}116 * \\
128 *\end{array}$ & $\begin{array}{l}31.9 \\
31.9\end{array}$ & NBS \\
\hline 316L & Jacket & $\begin{array}{l}\text { RT } \\
4.5\end{array}$ & $\begin{array}{r}80 \\
200\end{array}$ & $\begin{array}{l}40 \\
80\end{array}$ & $\begin{array}{l}29.5 \\
31.9\end{array}$ & \\
\hline $\begin{array}{l}\text { Conductor Bundle Stack } \\
\text { mter-Turn } \\
\text { (Buttol Direction) } \\
\text { Inter-Laver } \\
\text { (Slotted G-11 Di rection) } \\
\text { IInop }\end{array}$ & $\begin{array}{l}- \\
-\end{array}$ & $\begin{array}{l}\text { IRT } \\
\text { RT }\end{array}$ & & & $\begin{array}{r}3.0 \\
21.4\end{array}$ & $\begin{array}{l}\text { LLL } \\
\text { LLL }\end{array}$ \\
\hline
\end{tabular}

* $120 \mathrm{ksi}$ was used for desigrs. LLL will purgue obtaining $120 \mathrm{ksi}$ minimuril yiteld strength 
Table 2.2. Magnet Structural Safety Factors

\begin{tabular}{|c|c|c|c|}
\hline \multirow[b]{2}{*}{ Structure or Condition } & \multicolumn{2}{|c|}{ Factor 2 Safety } & \multirow{2}{*}{$\begin{array}{l}\text { Iffe } \\
\text { Factor } \\
\end{array}$} \\
\hline & Yield & Iltimate & \\
\hline Case, Jacket, Intercoil & 1.5 & - & 4.0 \\
\hline Support Structure & 1.5 & $3.0^{*}$ & 4.0 \\
\hline
\end{tabular}

* Based on ASME Codes tequiren.ants 


\section{ANALYSIS}

\subsection{INTRODUCTION}

The objective of the MFTF conductor stress analysis was to calculate a realistic upper bound for the conductor strain using the existing GDSAP model; conductor winding gaps and plasticity effects were to be reflected in the analysis (Ref. 3). Predicted conductor pack stresses and strains were to be determined within the limitations of the existing six-conductor element idealization previously modeled (see Figure 1. 1). To accomplish this task, we had proposed a piecewise linear analysis of the conductor pack.

Subsequent to contract go-ahead, we were directed by LLL to rescope this task to address the sensitivity of conductor stress to winding gaps (Ref. 4). It was agreed that the analysis would be redefined to "linearly" approxdmate the effects of 0.005 and 0.010 inch per turn gaps in the major and minor radius radial direction. In addition, it was recognized that transverse gaps tid not contribute significantly to conductor hoop tension stresses.

\subsection{BASELINE}

The initial task of this analysis was to establish a baseline conductor pack connectivity scheme that adequately reflected the conductor pack's response to applied electromagnetic and thermal loads. The conductor pack is a series of nlobium titanium superconductors imbedded in a copper matrix, separated by insulating materials of various geometric configurations (see Figures 3.1 thru 3.4). As illustrated in Figure 1.1, the conductor pack is modeled as an array of axial load carrying rod elements. The axial (hoop) stiffness of the pack is represented by six sets of hoop rod elements. These hoop elements are connected to the case and to one another with rod elements that represent the transverse stiffness of the pack. The conductor pack, however, is capable of sustaining tensile loads only in the hoop direction and thus the modeled conductor pack transversa rod connectivity should reflect this physical requirement.

Figure 3.5 is the orientation diagram for all subsequent conductor pack connectivity schematics. Brielly, double line rod elements reflect true areas; dark (solid) rods indicating tension loads and light rods indicating compression loads. The + and symbols indicate the sign of the residual load of rods with areas set equal to 0,01 sq. in. 


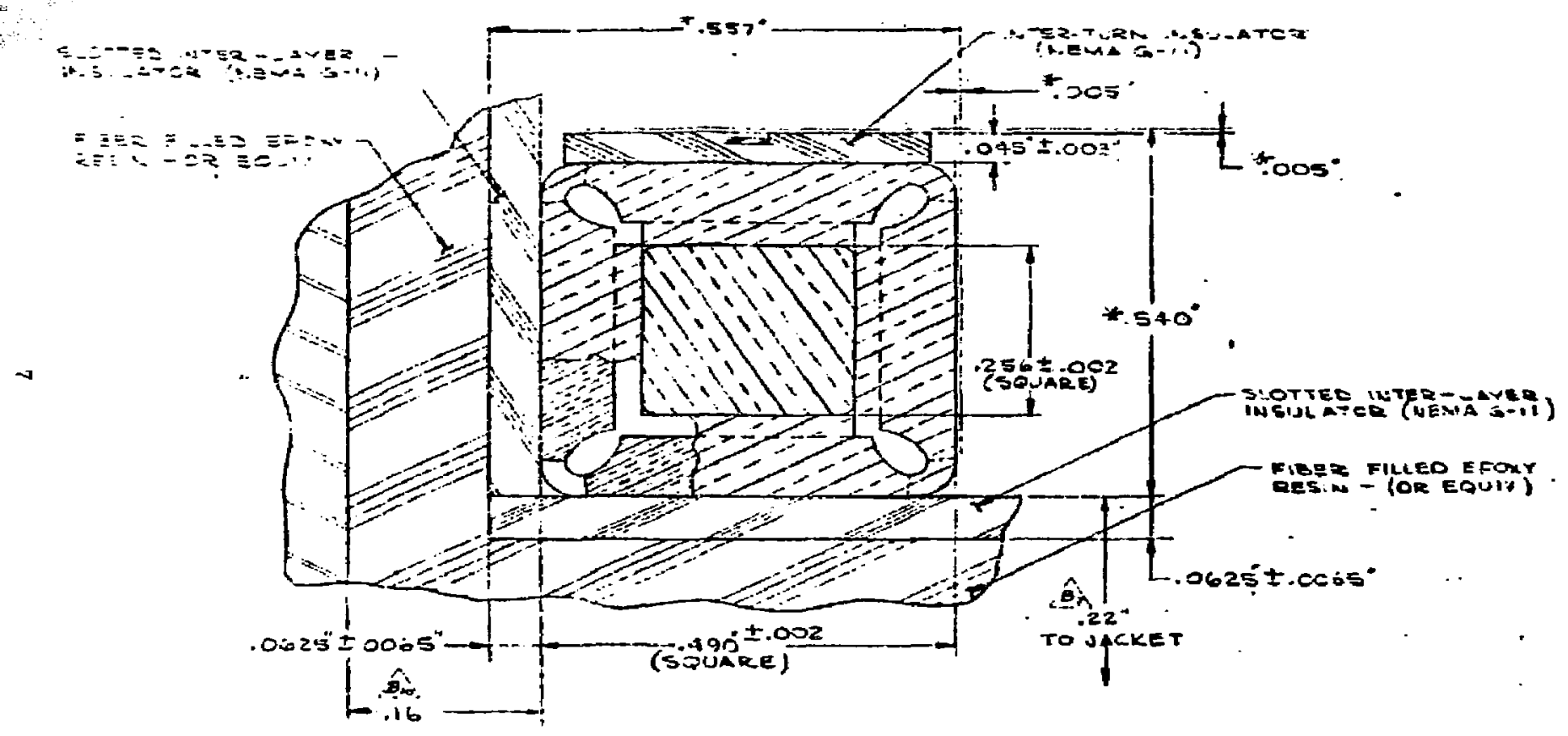

Figure 3.1. MFTF Conductor/Insulation Cross-Section 


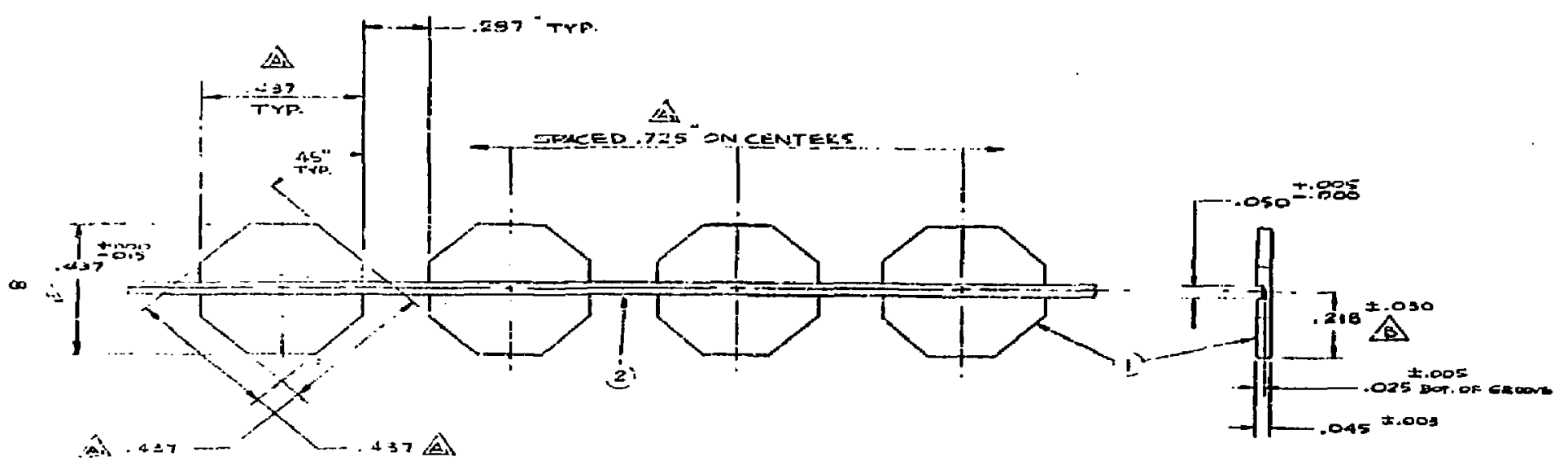

DIMENSIOMS TYPICDL

ICALE - $4 x$

Figure 3.2. MFTF Insulation Buttons 

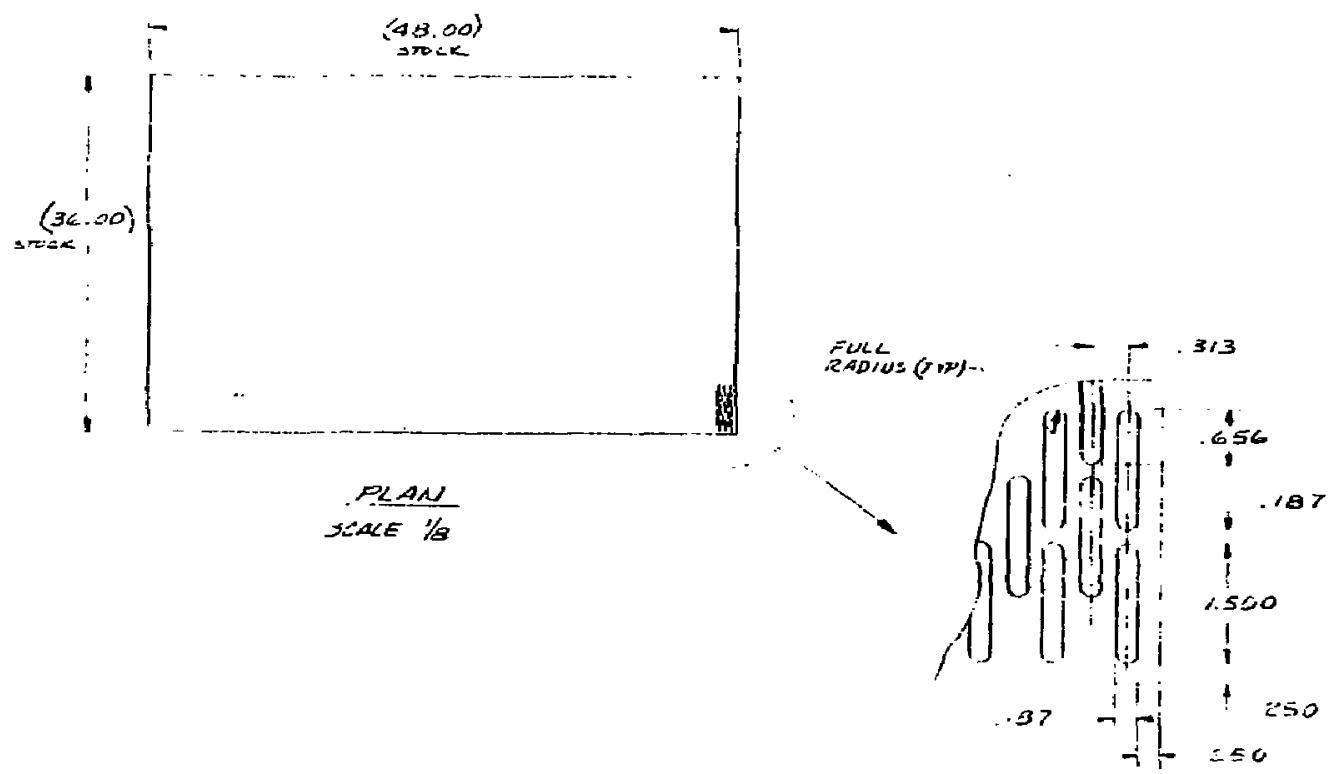

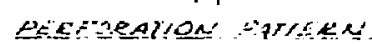
TrDicAL fOR Fith SirST

Figure 3.3. MFTF Slotted Insulation 


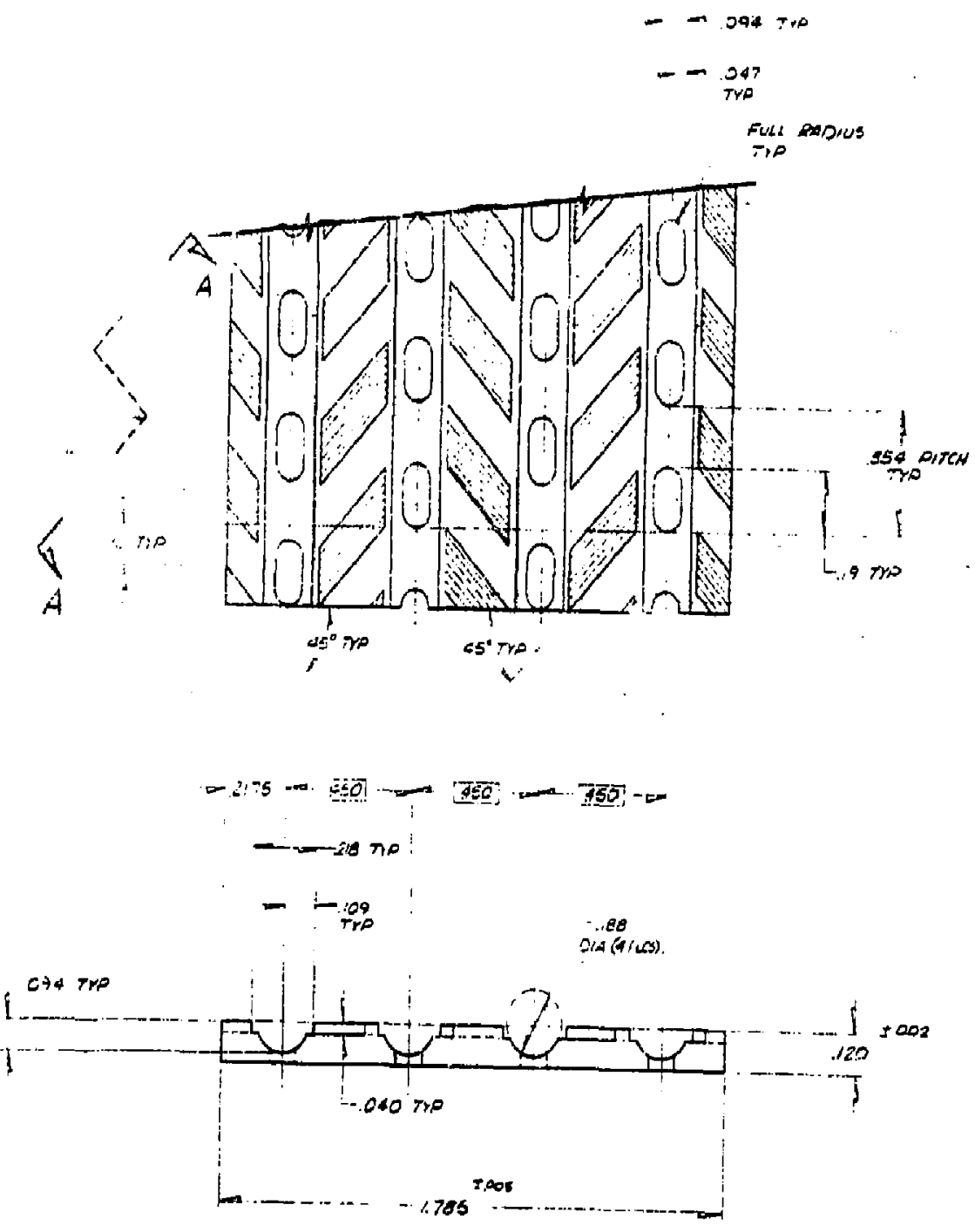

Figuro 3.4. MFTF Superconductor Copper Wrap 


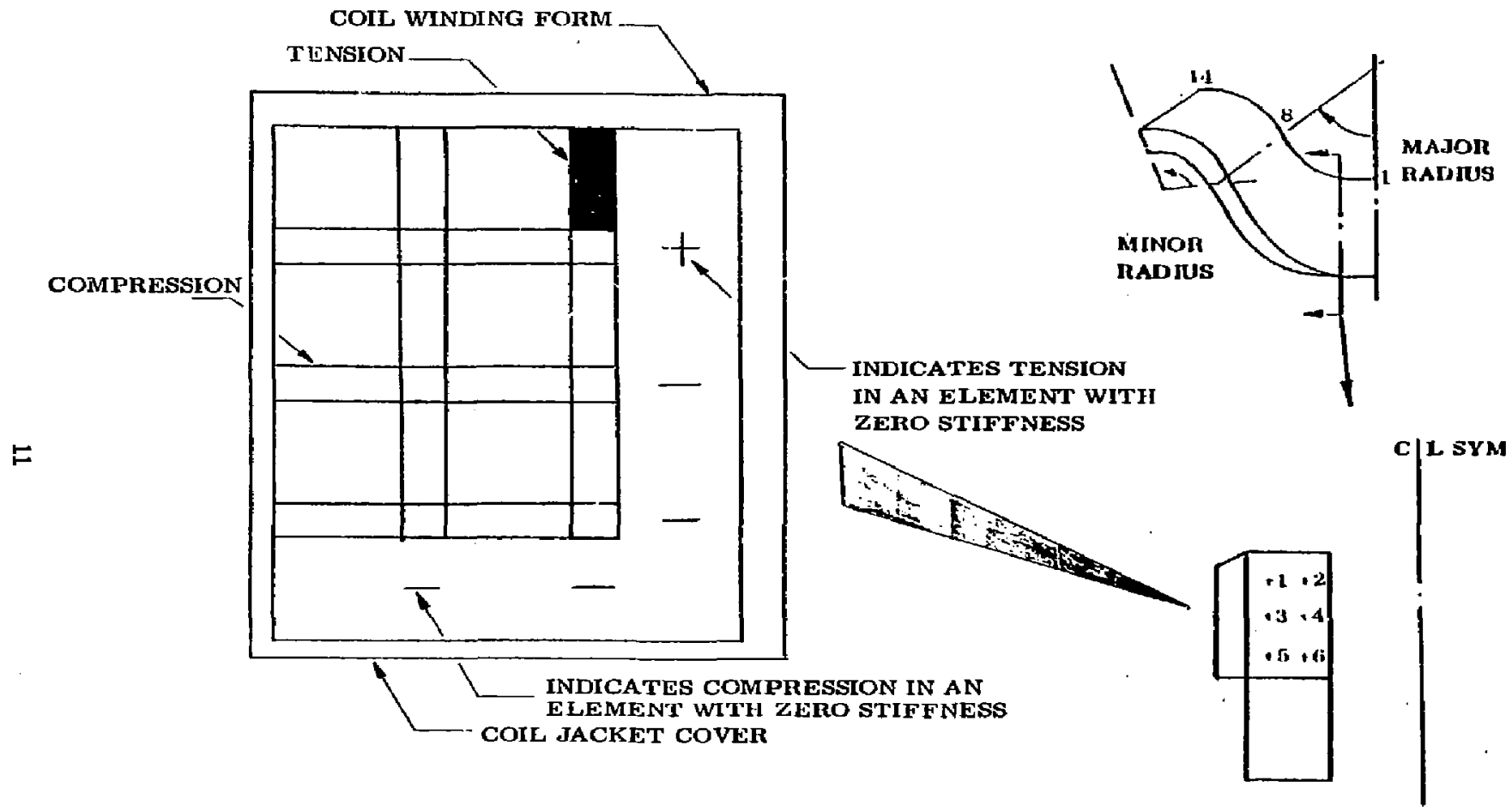

Figure 3. 5. Orientation Diagram for Connectivity Schematica 
Figure 3.6 displays the conductor connectivity schematic that was initially assumed to most accurately represent the conductor pack. Under the influence of magnetic loads, it can be seen that flettious tensile loads exist at planes 2,3 , and 5 in the radial direction of the major radius; these radial pressures are 301,489 , ynd 257 psi, respectively. In the minor radius in tice radial direction the top layer in planes 9 thru 14 all reflect fictitlous tension loads. These pressures range from 2429 psi at plane 9 to $938 \mathrm{psi}$ at plane 14 (about 900 psi average pressure).

Thermal load case results reflect tenslon loads in almost all conductor stabilizing rods in the radial direction of major radius, while the combined results (thermal plus magnetic) nearly dupiicate the magnetic load case results. Thus, it can be seen graphically that the applied magnetic loads completely dominate the assumed connectivity scheme as was expecter. Thus, it was decided to consider magnetic loads only during all subsequent conductor pack connectivity studies.

The fictitious transverse tension stresses that are illustrated schematically in Figure 3. 6 for the initial connectivity scheme reflect the complex interactions between the conductor pack and the case and between the separate elements of the conductor pack itself. Some of the phenomena that contribute to the development of transverse tension in the conductor pack model are the following.

1. During the application of applied magnetics loads the conductor pack undergoes electromagnetic constriction.

2. There is an interaction between locally applied magnetic loads and overall conductor hoop stresses.

3. Conductor case deflections affect the validity of the assumed conductor pack connectivity scheme.

4. Of secondary importance are several small discrepancies that exist between the finite element model applied loads and the true electromagnetic load uistribution.

The load discrepancies mentioned in item four developed during the MFTF design analysis task, when the finite element model was constantly undergoing small geometric changes. The electromagnetic loads which were based on a particular model geometric configuration were not updated when the model geometry was changed. Thus, discrepancies arose because of the location for a particular load vector may not be the same as the location used to calculate the load. However, the total applied load is correct and discrepancies of this type will not have a significant effect on the overall results. Also, as the object of this study is to report sensitivities rather than absolute numeric results, the impact of these load discrepancies is further reduced.

The resulting conductor hoop stresses for the initial assumed connectivity scheme are sbown in Figure 3.7. As previously precticted (Ref. 5), idealized conductor number 2 
SAP BASELINE MODEL ROD RESULTS (RUN NO, 1)

MAGNET PLANES

MAGNETIC

LOAD CASE

HESULTS
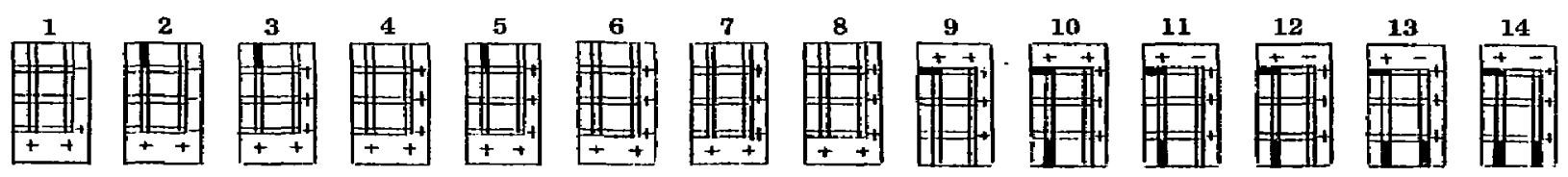

$\begin{array}{ll}\text { E } & \text { THERMAL } \\ \text { LOAD CASE } \\ \text { RESULTS }\end{array}$
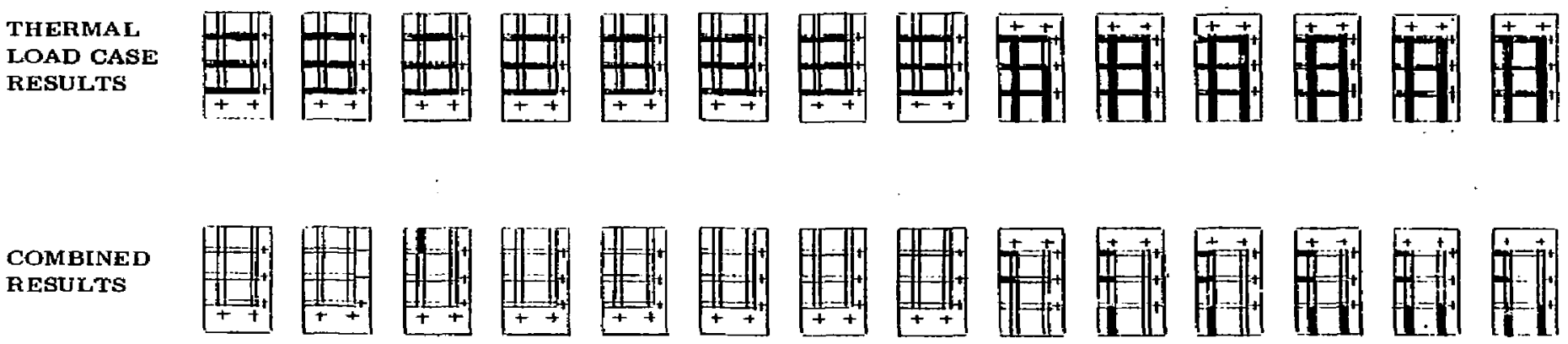

LEGEND:

SOLID ROD ( $)$ INDICATES TENSION

LIGH'T ROD ( =) INDICATES COMPRESSION

+ OR - INDICATES TENSION OR COMPRESSION IN TRANSVERSE ELEMENTS WHOSE STIFFNESSES HAVE BEEN ELLMINATED

Figure 3.6. MFT Conductor Pack Connectivity scheme No. . 
RUN NO. 1 RESULTS
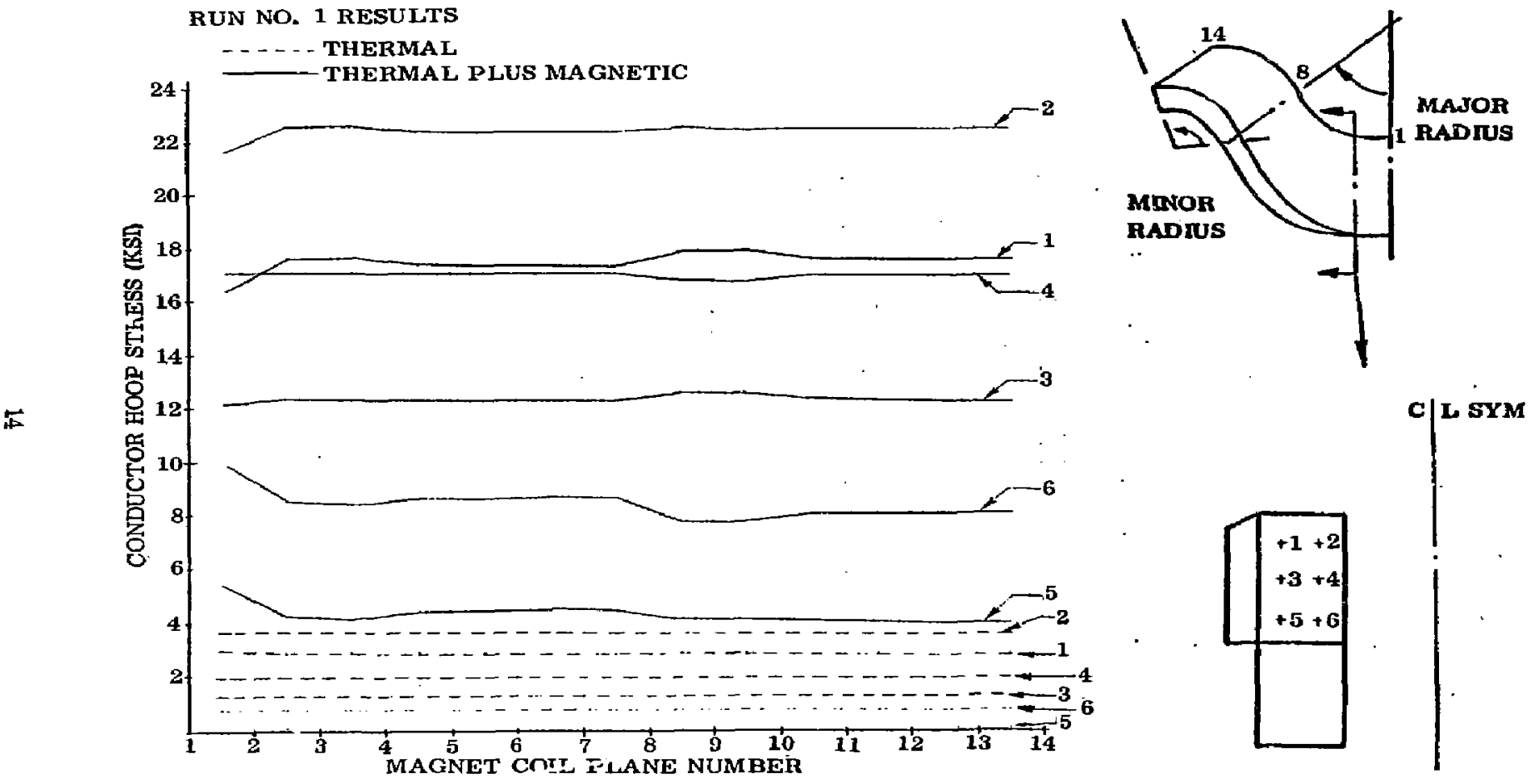

占

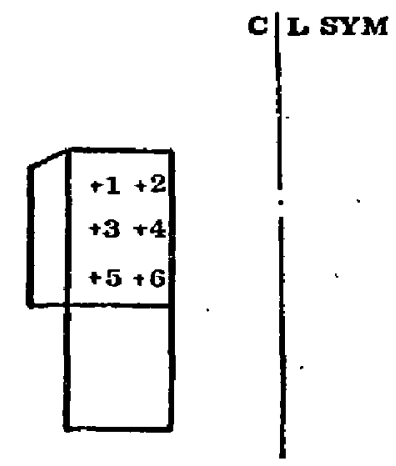

Figure 3.7. MFTF Conductor Pack Connectivity Scheme No. 1

F. E. Model Hoop Stresses 
has the highest tension, 22,500 psi, for the combined thermal and magnetic loading condition. It can also be seen that the inside turns $(2,4,6)$ have a bigher boop tension stress than their corresponting outside turns $(1,3,5)$ as was expected.

After analyzing the results of connectivity scheme No. 1, it wis decided to model the conductor pack as a partially free standing pack in the minor madius. Figure 3.8 presents this connectivity scheme and analysis load case results. Figure 3.9 compares the resulting conductor hoop stuesses of connectivity schomes 1 and 2 . As can be seen, the relationship between the magnitudes of the six idealized conductors is no longer correct (1. e., conductor No. 4 has a blgher hoop censile load than hoop conductor No. 2). At that time, this result was believed to be dite to the radial tension loads at planes $2,3,4$, and 5 of 301, 490, 191, and 257 psi, respectively. Subsequent analysis review however indicated that this was not the case, as excessive conductor deflections (in excess of $\left.1 . v^{\prime \prime}\right)$ were being incluced in the free standing minor radius region.

A total of three adititional free standing connectivity schemes $(3,4$ and 5$)$ were analyzed before the concept was abandoned. Details of these connectivity schemes and resulting conductor hoop stresses are shown in Figures $3.10,3.11,3.12$ and 3.13 , $3.14,3.15$, respectirely. Connestivity scheme No. 3 and 4 provided for some free standing conductors in both the major and minor radius. In both cases, deflections approaching $1.8^{\prime \prime}$ were experienced in the major radius area. Connectivity scheme No. 5 provides for free standing conductors in the minor radius area only; this schęme was also invalidated because of resulting $1.0^{\prime \prime}$ conductor deflections.

Connectivity scheme No. 6 is shown graphically in Figure 3.16. This scheme provides for no free standing conductors (1. $e_{*}$, at least one stabilizing conductor in every row or column is connected to the case). A fictitious cadial pressure of approxdmately 600 psi is being applied to conductor No. 1 in the minor radius. At this time, it was decided that within the limitations of the existing model and analysis technique, connectuvity scheme No. 6 would be adequate and serve as the baseline model for all subsequent analyses. Results of the baseline analysis are presented in Section 4.

\section{$3.30 .005^{\prime \prime}$ GAP HOMOGENZATION}

To determine the sensitivity of conductor hoop stress to manufacturing intercouductor winding gaps, a homogenization technique was used to develop idealized concuctor pack radial and transverse stiffness data. The following steps are utilized in this process:

1. Determine the average pressure in the conductor pack in the direction under consideration $\left(\mathrm{P}_{\mathrm{A}}\right)$. 
SAP BASELINE MODEL ROD RESULTS (RUN NO. 2) MAGNET PLANES
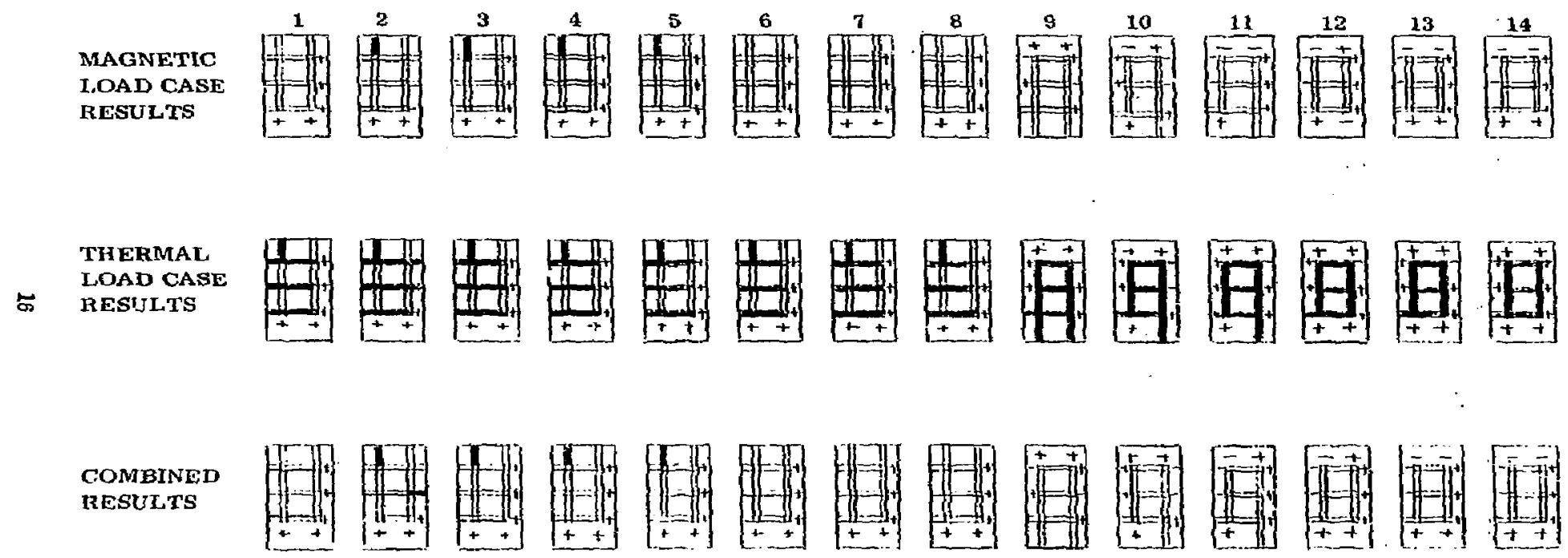

\section{LEGEND;}

SOLID ROD ( - ) INDICATES TENSION

IIGHT ROD ( $=$ ) INDICATES COMPRESSION

Figure 3.8. MFTF Conductor Pack Connectivity Scheme No. 2 

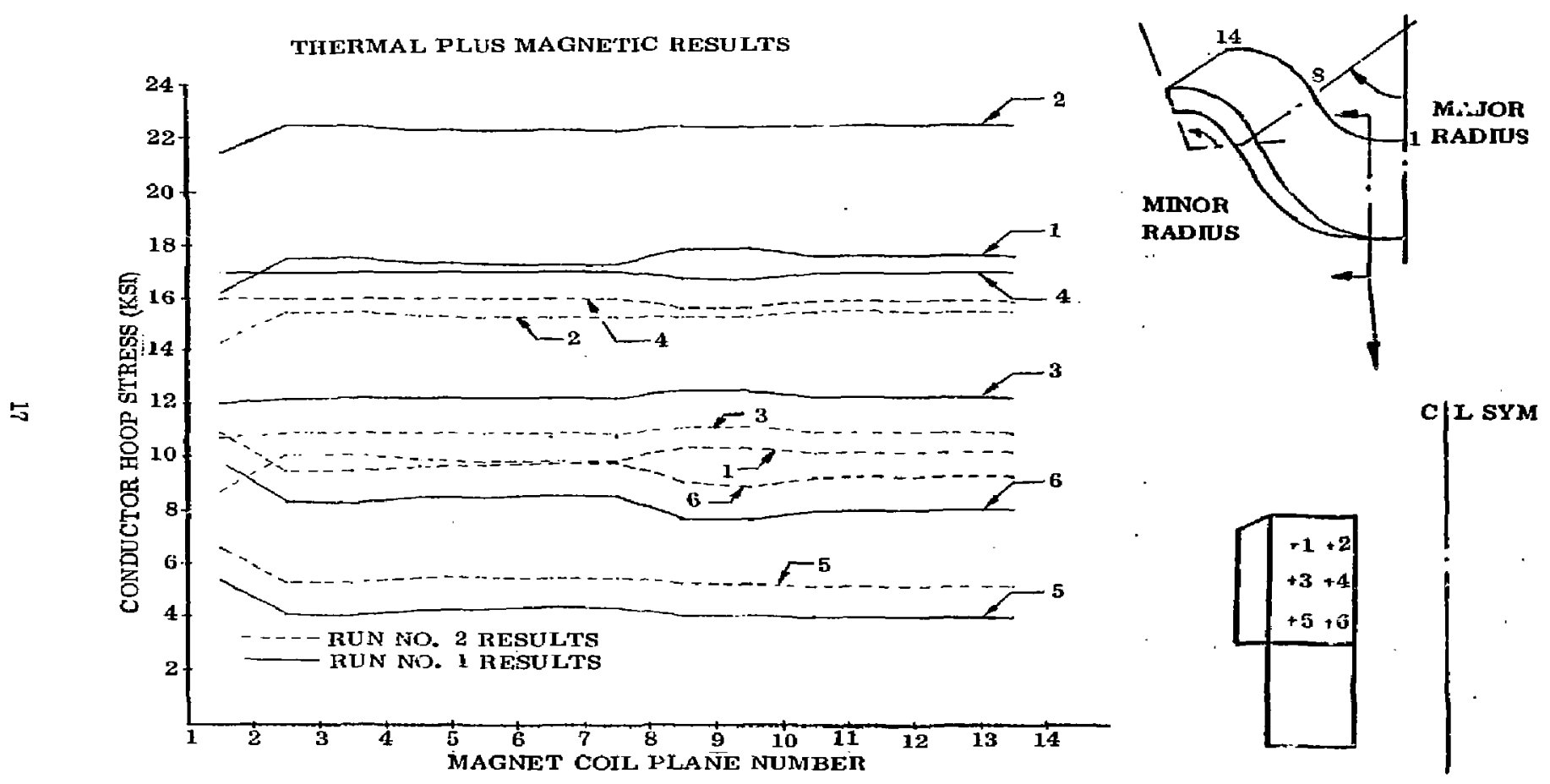

Figure 3.9. MFTF Conductor Pack Connectivity Scheme No. 1 and No. 2 F.E. Model Hoop Stress Cumparison 


MAGNETIC
LOAD CASESTS

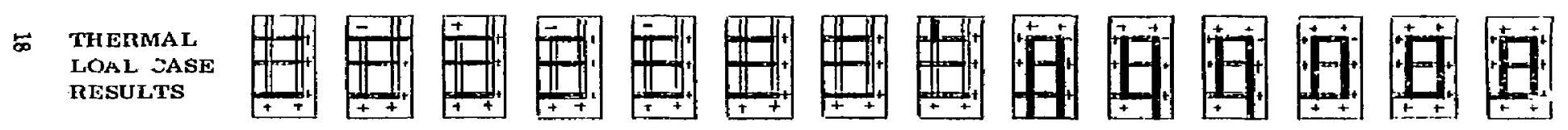

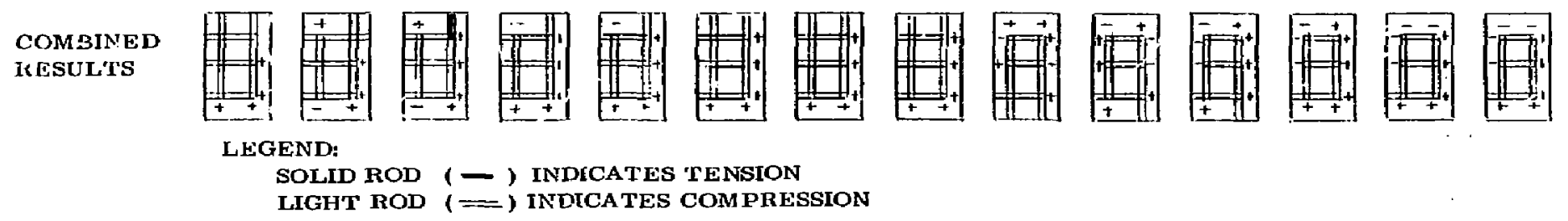

Figure 3.10. MFTF Conductor Pacl: Connectivity Scheme No. 3 
SAP BASELINE MODEL ROD RESULTS (RUN NO. 4)

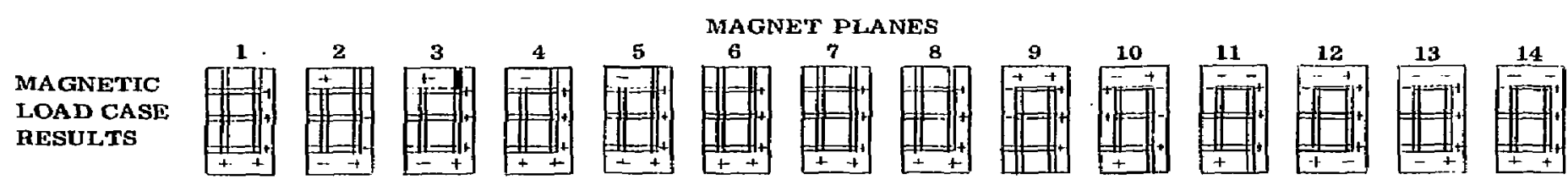

“"

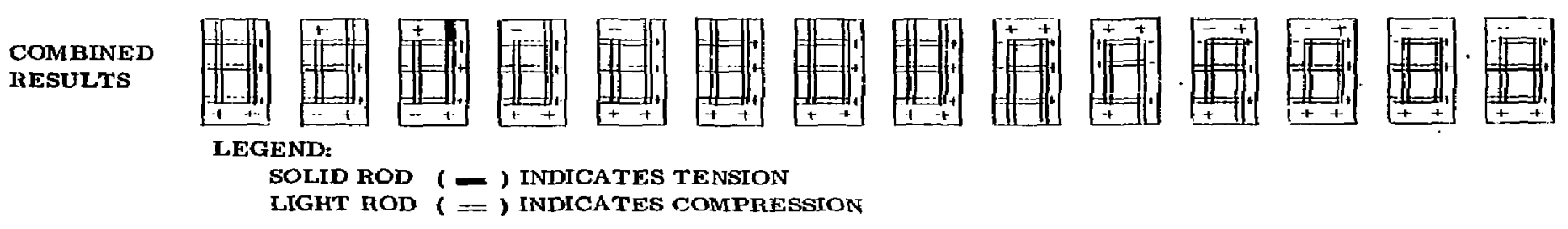

Fgure 3. 11. MFTF Conductor Pack Connectivity Scheme No. 4 
LOAD CASE

RESULTS
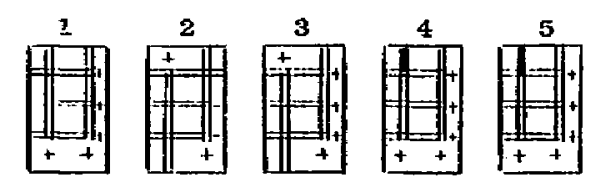

MAGNET PLANES
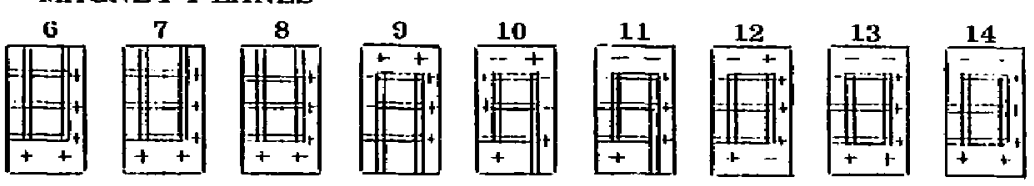

D THERMAL
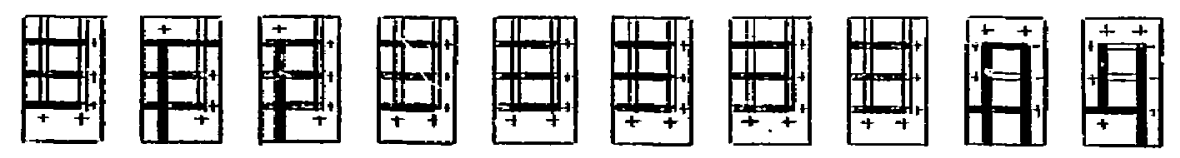

画国

国国

COMBINED
RESULTS
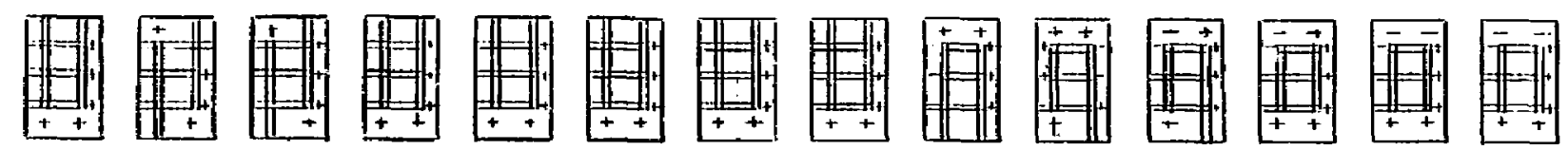

LEGEND:

SOLID ROD ( - ) INDICATES TENSION

LIGHT ROD ( =) INDICATES COMPRESSION

Figure 3. 12. MFTF Conductor Pack Connectivity Scheme No. 5 

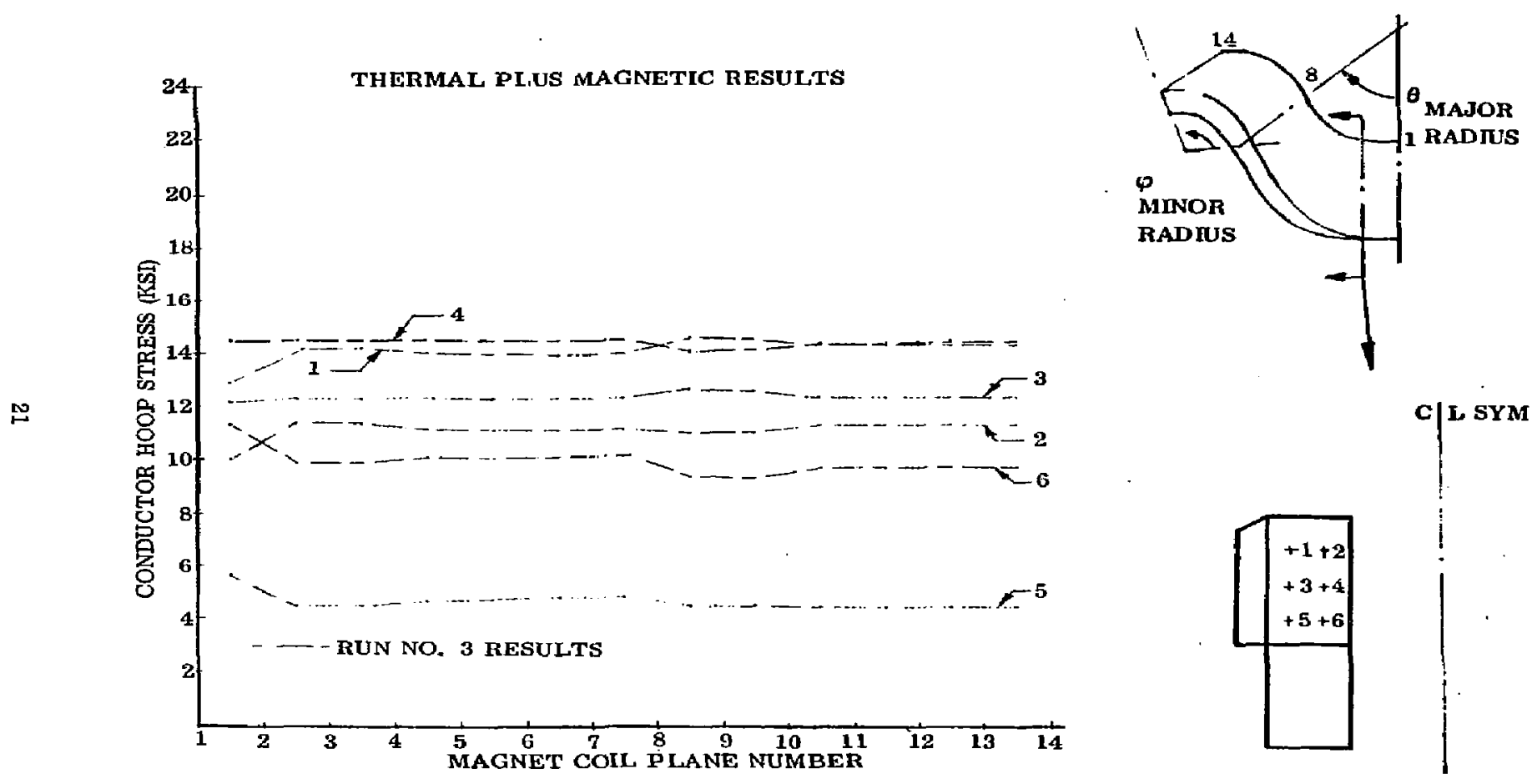

Figure 3.13. MFTF Conductor Pack Connectivity Scheme No. 3 F. E. Model Hoop Stresses 

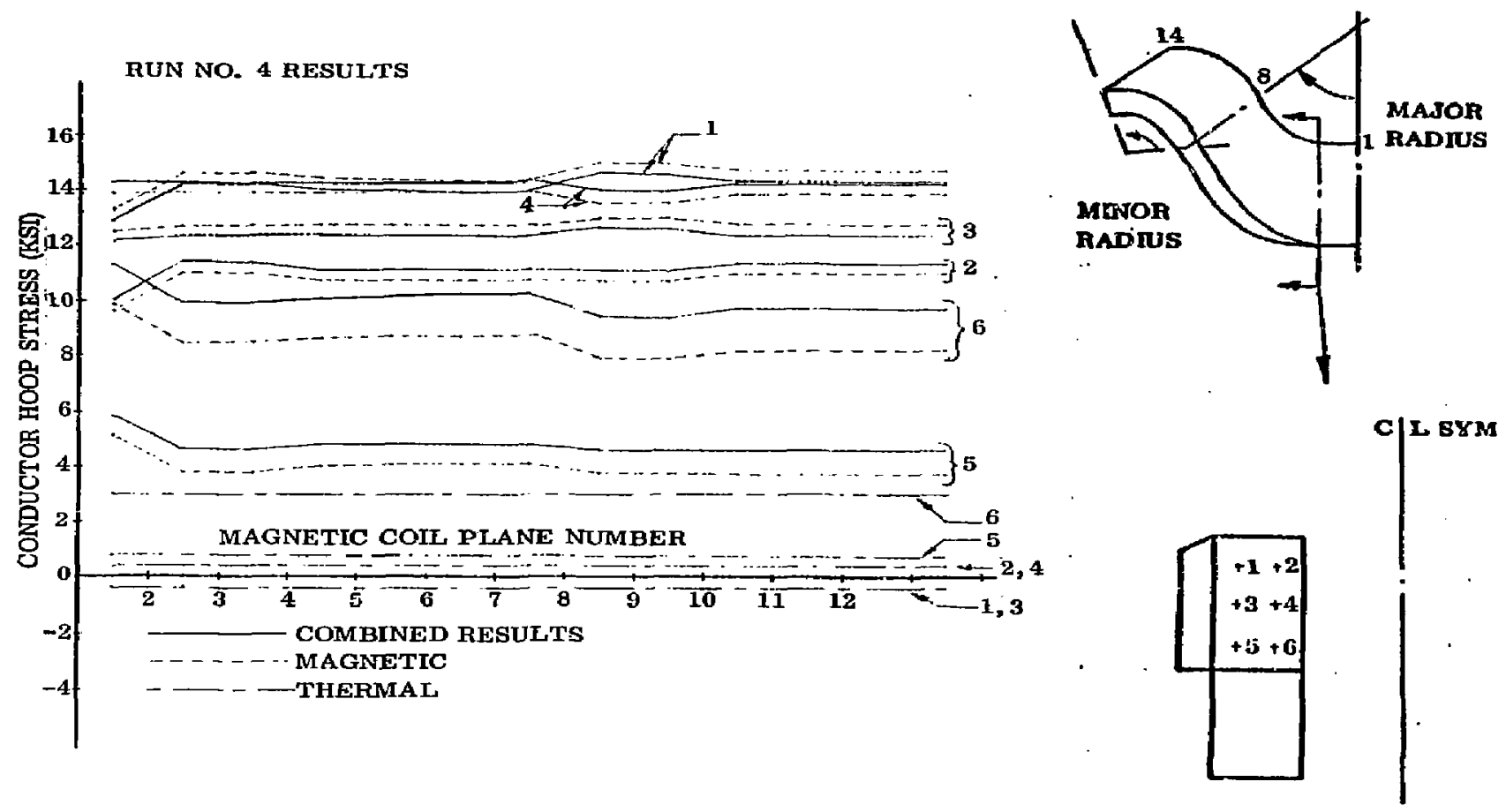

Figure 3.14. MFT Conductor Pack Connectivity Scheme No. 4 F. E. Model Hoop Stresses 

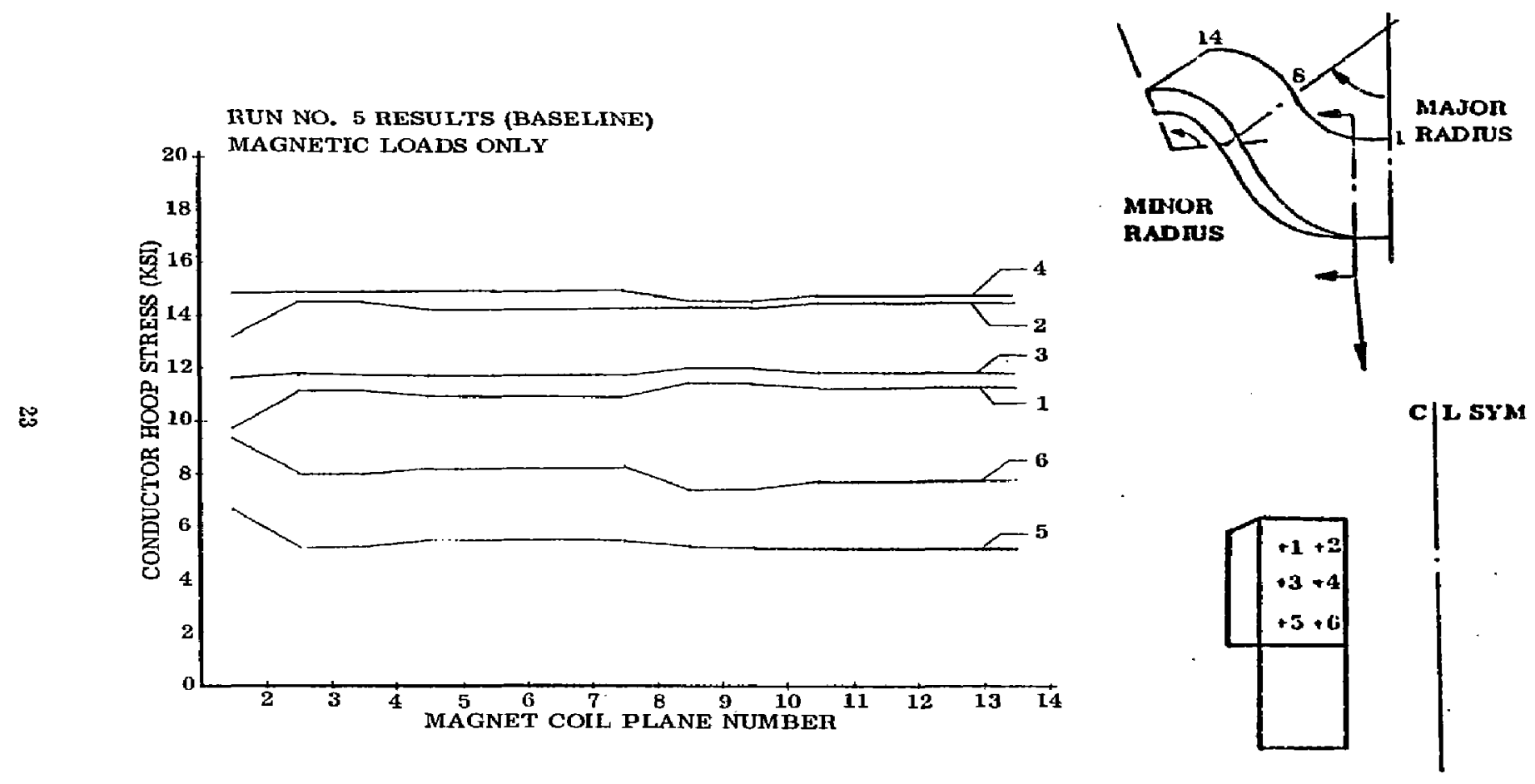

Figure 3. 15. MFTF Conductor Pack Connectivity Scheme No. 5 F. E. Model Hoop Stresses 
MAGNETIC

LOAD CASE

RESULTS
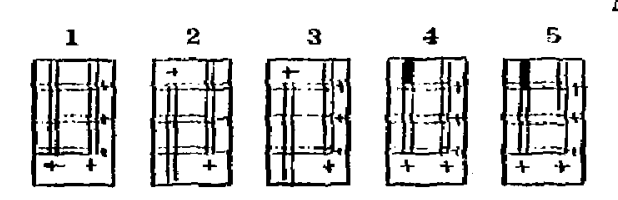

MAGNET PLANES
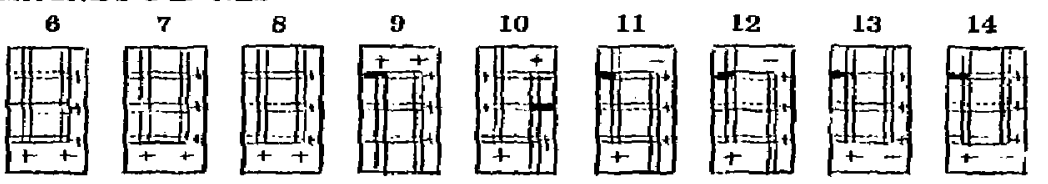

THERMAL
LOAD CASE
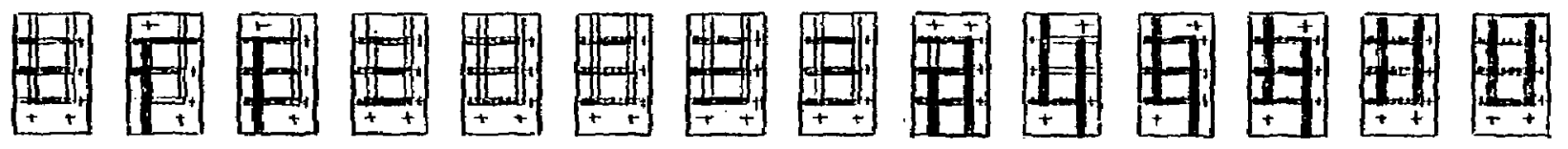

COMBINED
RESULTS
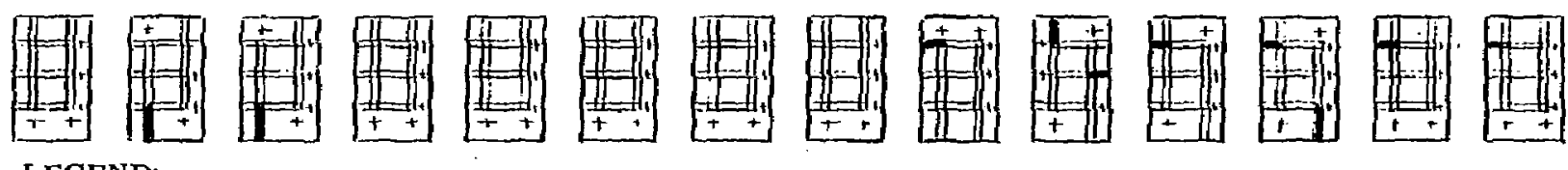

SOLID ROD ( - INDICATES TENSION

LIGHT ROD $q=$, INDICATES COMPRESSION

Figure 3. 16. MFTF Conductor Pack Connectuity Scheme No. 6 
2. Convert the winding gap (G) into an equivalent gap strain per unit conductor width $\left(\mathrm{C}_{W}\right)$.

$$
\text { i.e., } E_{G}=G / C_{W}
$$

3. Assume that this strain corresponds to the previously calculated average stress, $P_{A}$, and calculate an equivalent modulus $\left(E_{G}\right)$.

$$
\text { i.e., } E_{G}=P_{A} C_{W} / G
$$

4. Compute a homogenized modulus that reflects the reduced conductor pack stiffness.

$$
E_{T}=\frac{1}{\frac{1}{E_{G}}+\frac{1}{E}}
$$

Based on the results of baseline No. 6 , the average compressive stress in the conductor pack in the major radius in the radial direction was determined to be $2807 \mathrm{psI}$ (actual stresses ranged from $3900 \mathrm{psi}$ at plane 7 to $2013 \mathrm{psi}$ at plane 2). Likewise, the average compressive stress in the minor radius in the radial direction was computed to be $1380 \mathrm{psi}$ (stresses ranging from $403 \mathrm{psi}$ at plane 14 to $3214 \mathrm{psi}$ at plane 9 ). Using these average stresses, the 0.005 in gap per turn was homogenized into the following effective conductor pack stiffnesses:

$$
\begin{aligned}
& \text { Layer-to-Layer Direction: } E_{\text {eff }}=2.8300 \times 10^{5} \mathrm{psi} \\
& \text { Button-to-Eutton Direction: } E_{\text {eff }}=1.3922 \times 10^{5} \mathrm{psi}
\end{aligned}
$$

These calculated conductor pack stiffnesses were then input into the baseline No. 6 connectivity scheme finite element model and analyzed. Results of this analysis are presented in Section 4, Results.

\subsection{010" GAP HOMOGENIZATION}

The 0.010 " winding gap conductor stress analysis was conducted using the same homogenization techniques as those described for the $0.005^{\prime \prime}$ gap study, Using the same average stresses presented previously, the $0.010^{\prime \prime}$ gap per turn was homogenized the following effective conductor pack stiffnesses:

$$
\begin{aligned}
& \text { Layer-to-Layer Direction: } E_{\text {eff }}=1.4851 \times 10^{5} \mathrm{psi} \\
& \text { Button-to-Button Direction: } \mathrm{E}_{\text {eff }}=7.2142 \times 10^{4} \mathrm{psi}
\end{aligned}
$$


An analysis using these reduced conductor pack stiffinesses was then concucted using the baseline No. 6 connectivity scheme. . Results of this analysis are presented in Section 4. 
RESULTS

\section{1 GENERAL}

Table 4.1 summarizes the typical conductor pack stress results of the various connectivity schemes analyzed. Comparison of computer runs 1 and 6 (both models contain no free standing conductors) appear similar, but the connectivity scheme used in run No. 6 reduced the fictitious radial pressure of $900 \mathrm{psi}$ to $600 \mathrm{psi}$ or approximately $30 \%$. Therefore, baseline No. 6 was selected for comparison purposes.

\subsection{BASELINE NO. 6}

A conductor hoop stress plot for the assumed baseline model configuration is shown in Figure 4.1. Of the six idealized hoop concuctors, conductor No. 2 has the highest hoop stress ( $\sim 17090 \mathrm{psi})$. A two-step extrapolation process was used to estimate the highest real conductor stress based on these results. In Figure 4.2, 2nd order polynomials were curve fit to the idealized conductor hoop stress results of baseline No. 6. Polynomials for conductor stack columns $1-3-5$ and $2,4,6$ were derived as follows (see Figure 4.3):

$$
\begin{aligned}
& (\sigma)_{1-3-5}=18009.889+423.707 \mathrm{x}+0.592 \mathrm{x}^{2} \\
& (\sigma)_{2-4-6}=21454.375+426.491 \mathrm{x}-0.302 \mathrm{x}^{2}
\end{aligned}
$$

These two polynomials were then used to extrapolate analysis results to the first row of conductors at $\mathrm{X}=-3.75^{\prime \prime}$,

$$
\begin{aligned}
& { }^{(\sigma)^{1-3-5} \mathrm{X}=-3.75}=16,428.47 \mathrm{psi} \\
& \langle\sigma)_{2-4-6}=19,850.79 \mathrm{psi} \\
& =-3.75
\end{aligned}
$$

A first order polynomial was then fit to these two data points and their corresponding $\mathrm{Y}$ coordinate for row interpolation

$$
\text { i. e., } \sigma=-402.63 \mathrm{Y}+30423.85
$$

This expression is evaluated at $Y=22.28$ in, to derive the peak conductor hoop stress of $21,453.25$ psi. 


\section{RESULTS}

\section{1 GENERAL}

Tabie 4. 1 summarizes the typical conductor fack stress results of the various connectivity schemes analyzed. Comparison of computer runs 1 and 6 (both models contain no free standing conductors) appear similar, but the connectivity scheme used in run No. 6 reduced the fictitious radial pressure of 900 psi to 600 psi or approximately $30 \%$. Therefore, baseline No. 6 was selected for comparison purposes.

\subsection{BASELINE NO. 6}

A conductor hoop stress plot for the assumed baseline model configuration is shown in Figure 4.1. Of the six idealized hoop conductors, conductor No. 2 has the highest hoop stress ( $17090 \mathrm{psi})$. A two-step extrapolation process was used to estimate the highest real conductor stress based on these results. In Figure 4.2, 2nd order polynomials were curve fit to the idealized conductor hoop stress results of baseline No. 6. Polynomials for conductor stack columns $1-3-5$ and $2,4,6$ were derived as follows (see Figure 4.3):

$$
\begin{aligned}
& \text { (J) })_{1-3-5}=18009.889+423.707 \mathrm{X}+0.532 \mathrm{x}^{2} \\
& \text { (c) }{ }_{2-4-6}=21454.375+426.491 \mathrm{X}-0.302 \mathrm{x}^{2}
\end{aligned}
$$

These two polynomials were then used to extrapolate analysis results to the first row of conductors at $\mathrm{X}=-3.75 "$,

$$
\begin{aligned}
& \text { (ธ) } 1-3-5 \text { } x=-3.75 \\
& (\sigma)_{2-4-6}=16,428.47 \mathrm{psi} \\
& =-3.75
\end{aligned}
$$

A first order polynomial was then fit to these two data points and their corresponding $\mathrm{Y}$ coordinate for row interpolation

$$
\text { i. e. } \sigma=-402.63 \mathrm{Y} \div 30423.85
$$

This expression is evaluated at $\mathrm{Y}=22.28$ in. to derive the peak concuctor hoop stress of $21,453.25$ psi. 
TABLE $4: 1$

CONDUCTOR PACK CONNECTIVTY STUDY RESULTS SUMMARY

\begin{tabular}{|c|c|c|c|c|c|c|}
\hline $\begin{array}{c}\text { Rod } \\
\text { ID\# }\end{array}$ & $\begin{array}{c}\text { Run \#1 } \\
\text { Results } \\
\text { psi }\end{array}$ & $\begin{array}{c}\text { Run \#2 } \\
\text { Results } \\
\text { psi }\end{array}$ & $\begin{array}{c}\text { Run \#3 } \\
\text { Results } \\
\text { psi }\end{array}$ & $\begin{array}{c}\text { Run \#4 } \\
\text { Results } \\
\text { psi }\end{array}$ & $\begin{array}{c}\text { Run \#5 } \\
\text { Results } \\
\text { psi }\end{array}$ & $\begin{array}{c}\text { Run \#6 } \\
\text { Results } \\
\text { psi }\end{array}$ \\
\hline $10-$ Cond \#1 & 14710 & 10640 & 14710 & 14710 & 11230 & 13760 \\
$23-$ Cond \#2 & 18930 & 15030 & 10960 & 10960 & 14440 & 17090 \\
$36-$ Cond \#3 & 10910 & 11320 & 12750 & 12720 & 11780 & 9608 \\
$49-$ Cond \#4 & 14910 & 15470 & 14040 & 13800 & 14740 & 12650 \\
$62-$ Cond \#5 & 3943 & 4444 & 3682 & 3709 & 5189 & 5254 \\
$75-$ Cond \#6 & 7287 & 7830 & 8203 & 8233 & 7736 & 7791 \\
\hline
\end{tabular}

NOTES:

- Run \#1 provides for no "free standing" conductors and has a fictitious radial pressure of approx. 900 psi applied to Conductor \#1 in the minor radius because of assumed conductivity scheme.

- Run "2 provides for some "free standing" conductors in the minor radius. Conductor pack deflections are $1.0^{\prime \prime}$ or more there.

- Run \#3 provides for some "free standing" conductors in both the major and minor radil. Conductor pack deflections are approaching $1.8^{\prime \prime}$ in the major radlus.

- Run \#4 provides for some "free standirig" conductors in both the major and minor radii. Conductor pack deflections are approaching $1.8^{\prime \prime}$ in the major radius.

- Run \#5 provides for "free standing" conductors in the minor radius only, Conductor pack deflections are $1.0^{\prime \prime}$ in the minor radius.

- Run \#6 provides for no "free standing" conductors. A fictitious radial pressure of approx. $600 \mathrm{psi}$ is being applied to Conductor $\# 1$ in the minor radius because of assumed connectivity scheme. 

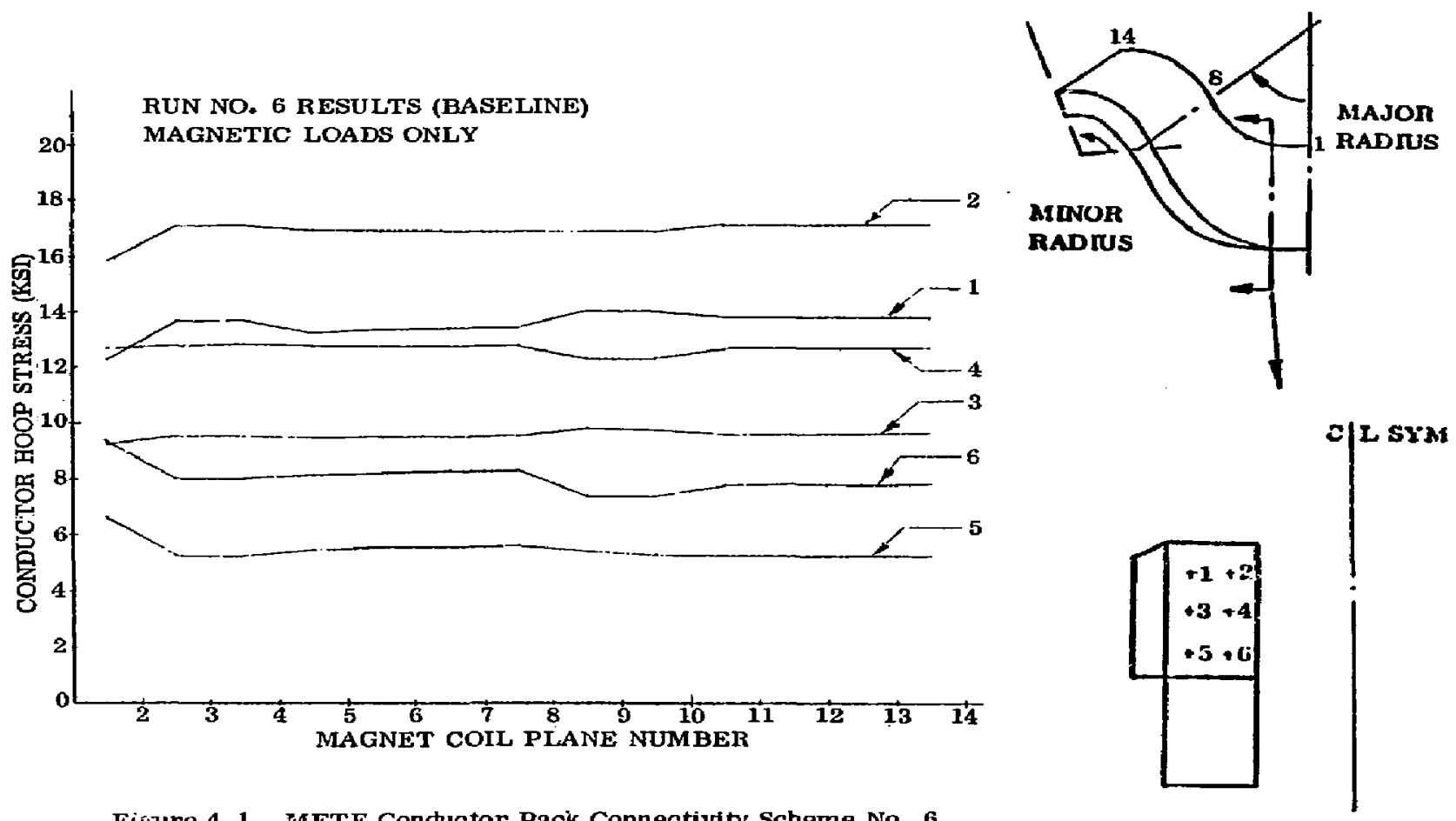

Figure 4. 1. MFTF Conductor Pask Connectivity Scheme No. 6 F. E. Model Hoop Stresses 

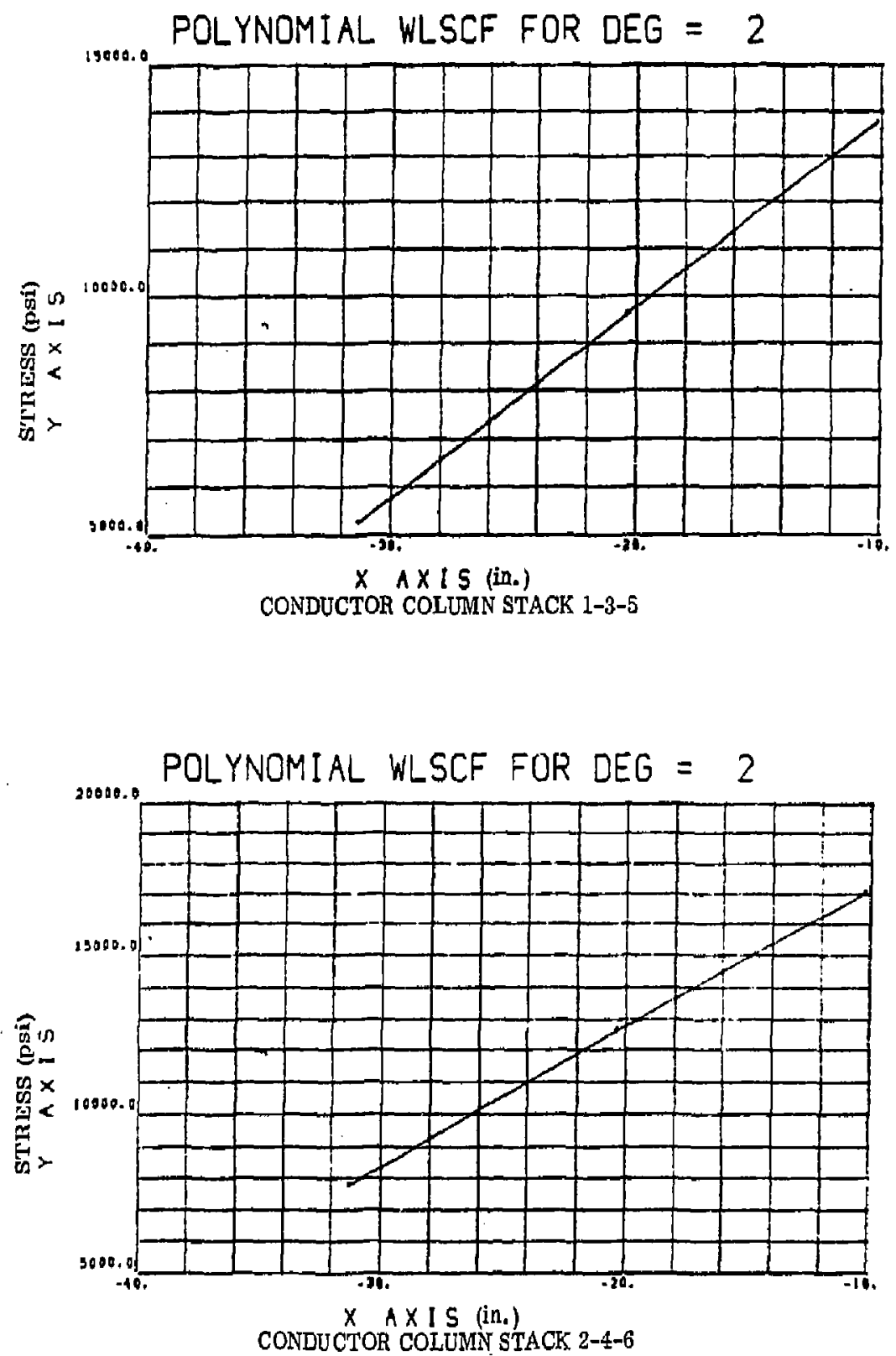

FIGURE 4.2. BASELINE NO. 6 - CONDUCTOR HOOP STRESS CURVE FIT RESULTS 


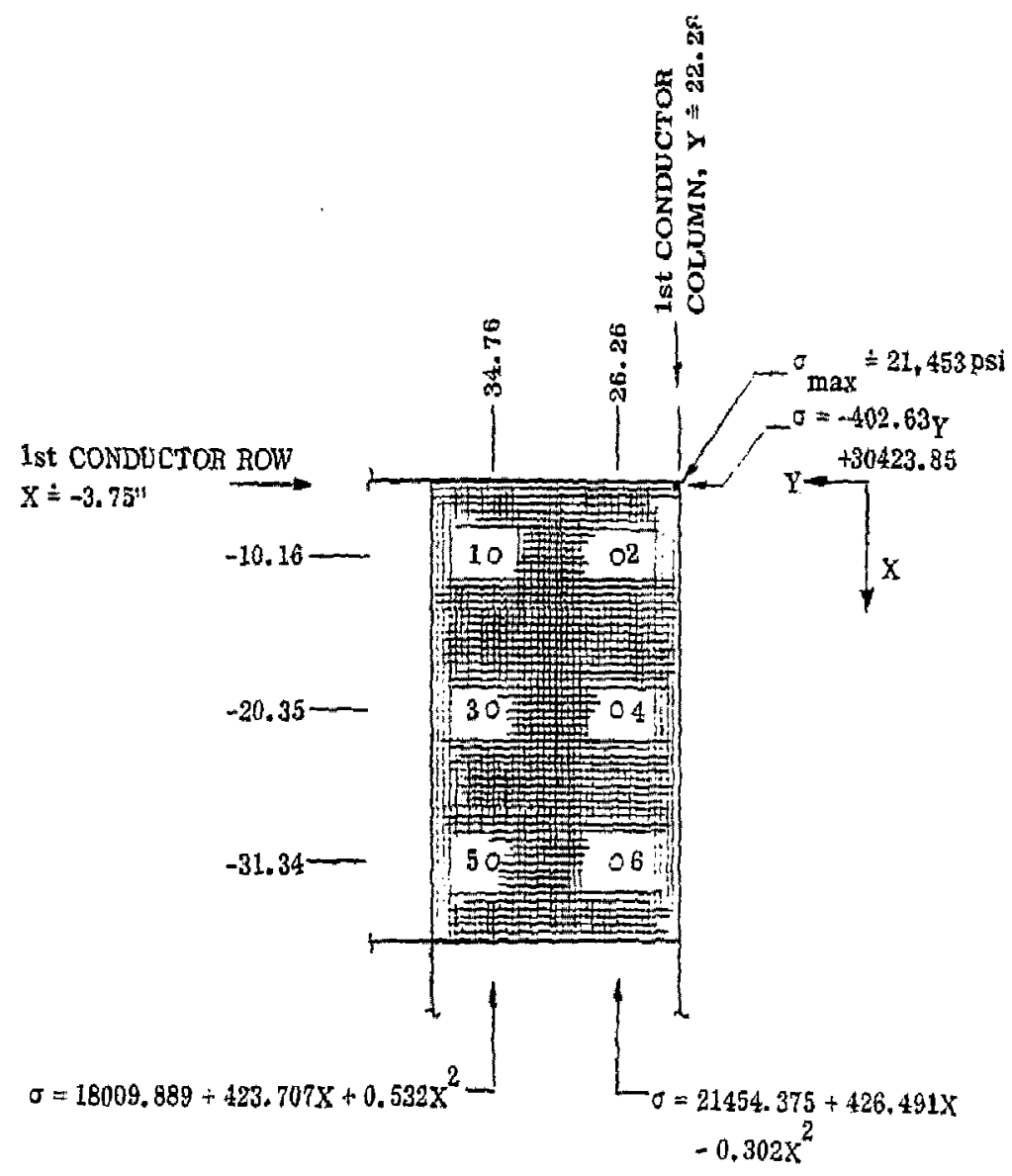

Figure 4.3. MFTF Conductor Pack Hoop Stress Extrapolation Scheme 
Appendix A contains the complete SAP finite element model output and selected conductor pack stress and strain data for this analysis.

\section{$4.30 .005^{\prime \prime}$ GAP HOMOGENIZATION}

Figures 4.4 and 4.5 present the conductor pack results for the $0.005^{\prime \prime}$ gap per turn homogenization study. Comparison of these results with those previously presented for the baseline model indicate that

1. Conductor elements on the inside of the major radius (i. $e_{1}$, conductors 2,4 , and 6) tend to carry more of the electromagnetic load in hoop tension as the effective stiffness in the radial and transverse clirections is decreased.

2. Conductor elements on the outside of the major radius (i.e., conduciors 1, 3, and 5) tend to carry less of the electromagnetic load in hoop tension as the effective stiffness in the radial and transverse directions is decreased.

Appendix B contains the complete GDSAP finite element model output for this analysis.

\subsection{010" GAP HOMOGENIZATION}

The results for the $0.010^{n}$ gap homogenization study are presented in Figures 4.6 and 4. 7. The same trends in conductor hoop stress that were reported in paragraph C (0.005" Gap Homogenization Results) are also apparent here, 1. e. , decreasing coniuctor pack transverse and radial stiffness causes model conductors 2,4 , and 6 to carry more electromagnetic load in hoop tension while model conductors 1,3 , and 5 carry less electromagnetic load in hoop tension.

The complete GDSAP finite element model output for the analysis is contained in Appendix C.

\subsection{PARAMETRIC COMPARISON}

Table 4.2 and Figure 4.8 present conductor hoop tension results as a function of analysis winding gap size. The data in Table 4.2 was used to derive peak conductor pack hoop stresses for each analysis case. The predicted results for the 0.005 " and $0.010^{\prime \prime}$ gap analyses are almost identical being 19,311 and $19,206 \mathrm{psi}$, respectively. As previously presented, the predicted peak hoop stress for the baseline analysis case was $21,453 \mathrm{psi}$. The decrease in predicted conductor boop stress with increased winding gap size is contrary to anticipated results and believed to be a consequence of the fictitious radial tension logd applied throughout the minor radius (see Figure 3.16). 
SAP 0.005" GAP HOMOGENEZATION MODEL ROD RESULTS
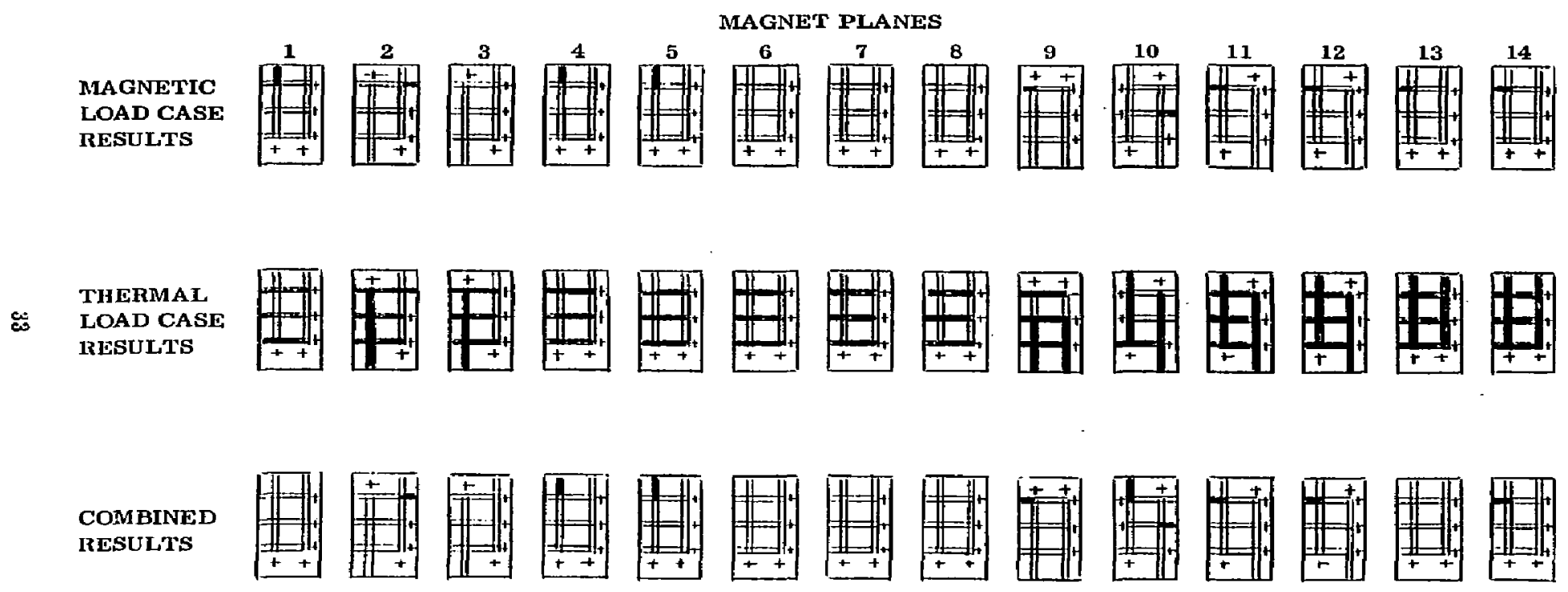

LEGEND:

SOLID ROD (-) INDICATES TENSION

LIGHT ROD $(=$ ) INDICATES COMPRESSION

Figure 4.4. MFTF Conductor Pack Connect vity Scheme No. 6 for 0. 005 Inch Winding Gap Homogenization 

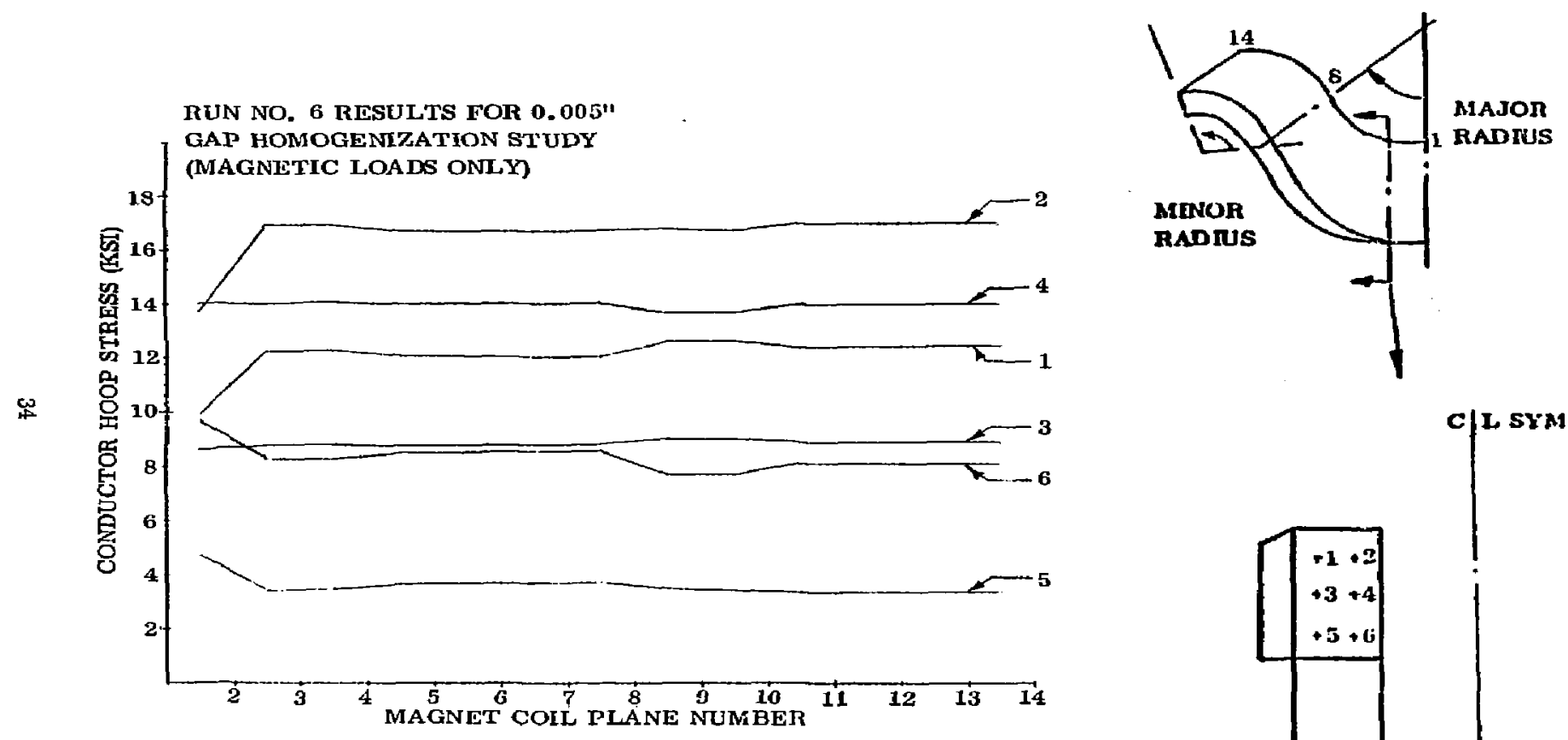

Figure 4.5. MFTl Conductor Pack Connectivity Scheme No. 6
F. E. Model Hoop Stresses for 0,005 Inch Winding Gnp Itomogenization
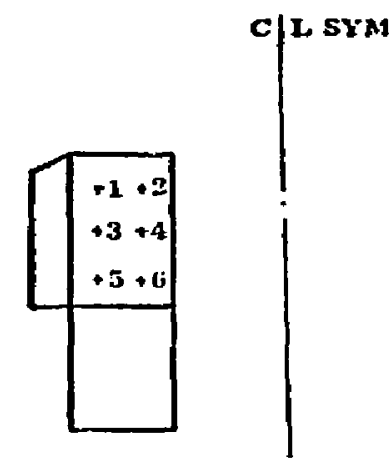
MAGNETIC
LOAD CASE
RESULTS
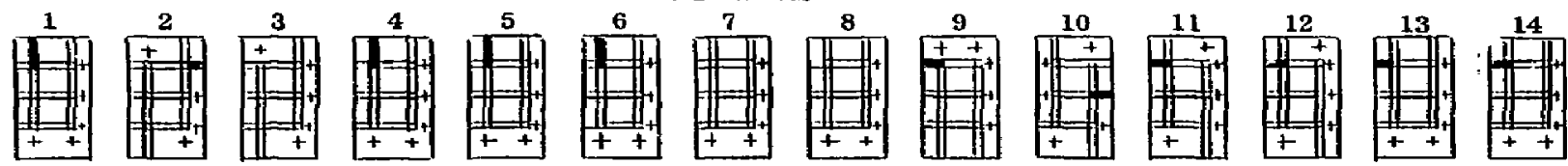

ఱ

THERMAL LOAD CASE RESULTS
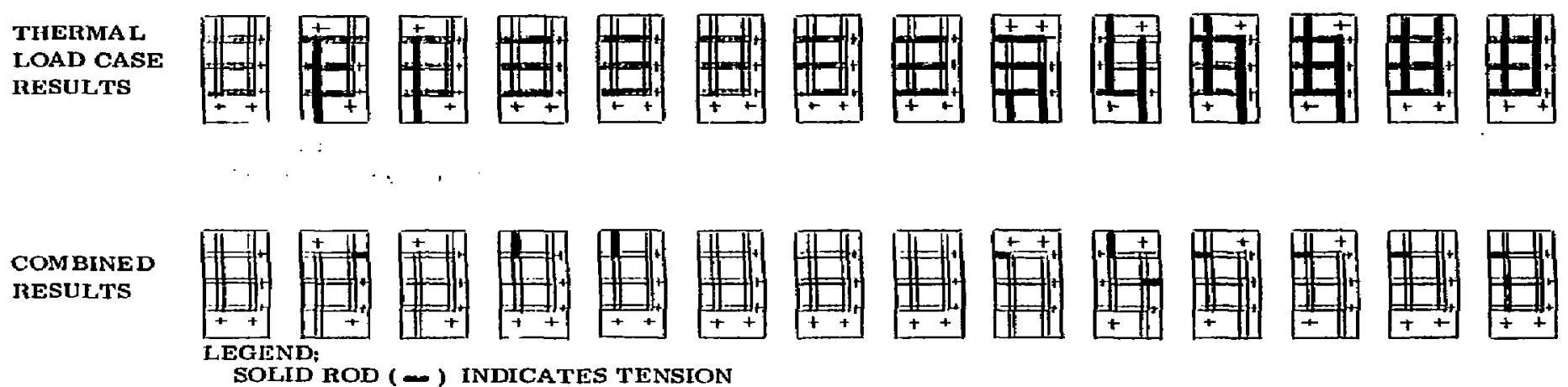

SOEID ROD (-) INDICATES TENSION

LIGHT ROD $=$ INDICATES COMPRESSION

Figure 4.6. MFTF Conductor Pack Connectivity Scheme No. 6

for 0.010 Inch Winding Gap Homogenization 
RUN NO, 6 RESULTS FOR 0.010"

GAP HOMOGENIZA TION STUDY
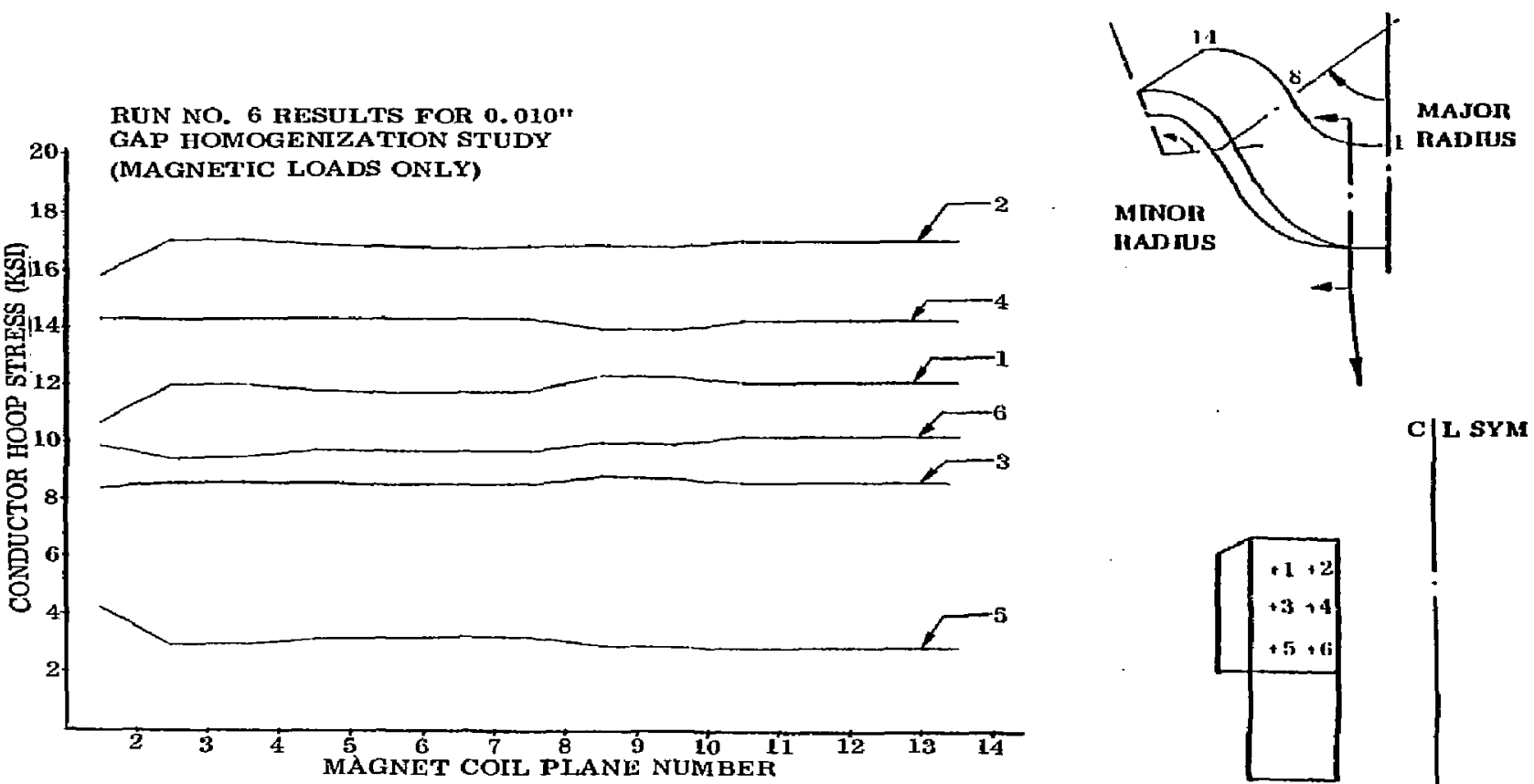

Figure 4. $\%$ MFTF Conductor Pack Connectivity Scheme No, 6 F. E. Model Hoop Stresses for 0.010 Inch Winding Gap Homogenization

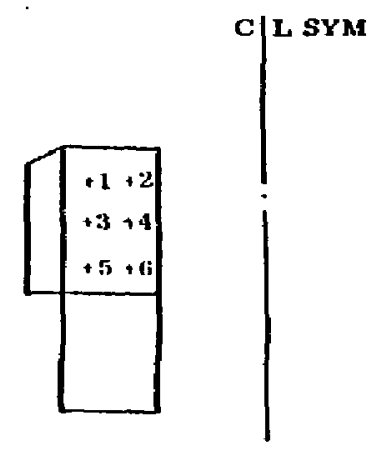


Table 4.2. Conductor Pack Winding Gap Homogenization Study Results Comparison

\begin{tabular}{|c|c|c|c|}
\hline $\begin{array}{l}\text { Rod } \\
\text { ID } \\
\text { No. }\end{array}$ & $\begin{array}{c}\text { Baseline \#6 } \\
\text { Results } \\
\text { (psi) }\end{array}$ & $\begin{array}{l}0.00{ }^{\prime \prime} \text { Gap } \\
\text { Results } \\
\text { (psi) }\end{array}$ & $\begin{array}{c}0.010^{\prime \prime} \text { Gap } \\
\text { Results } \\
\text { (psi) }\end{array}$ \\
\hline 10 - Cond. \#1 & 13760 & 12414 & 12144 \\
\hline 23 - Cond. & 17090 & 16943 & 17008 \\
\hline 36 - Cond, $\# 3$ & 9608 & 8860 & 8653 \\
\hline 49 - Cond. \#4 & 12650 & 13971 & 14248 \\
\hline 62 - Cond. \#5 & 5254 & 3390 & 2904 \\
\hline 75 - Cond. 6 & 7791 & 8082 & 8255 \\
\hline
\end{tabular}



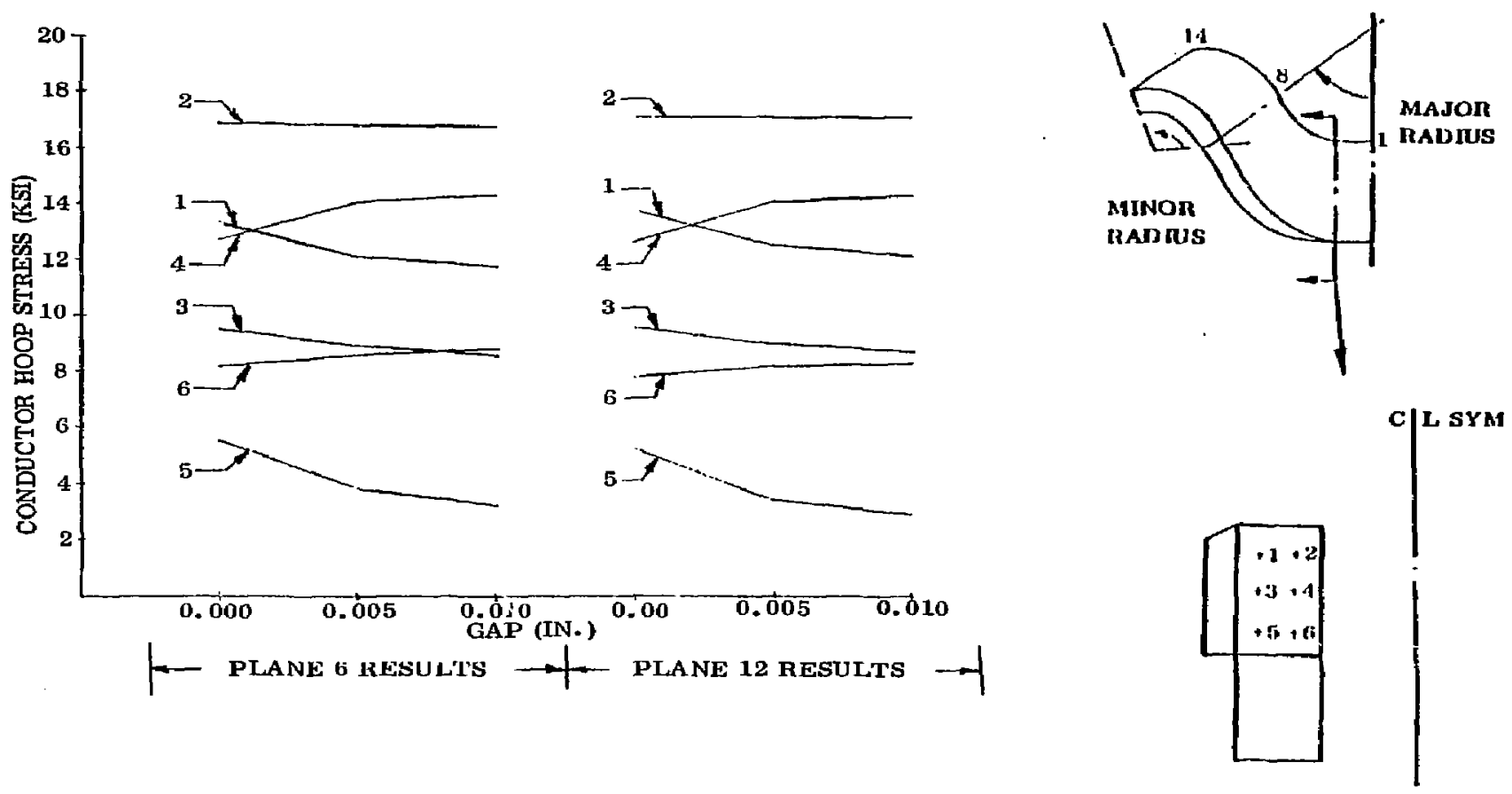

Figure 4.8. MF'IF Concluctor Hoop Stress as a Function of Winding Gup 


\section{CONCLUSIONS}

The analysis reported herein is based on linear elastic small deflection theory. For reason: of convenience and cost, non-linear gaps were idealized as reduced conductor pack stiffesses in this analysis to determine the sensitivity of the conchictor hoop stress to these winding gaps. Observing the limitatlons of this Idealization, the following can be reported with confidence.

1. Interwinding gaps analyzed $\left(0.005^{\prime \prime}\right.$ and $\left.0.010^{\prime \prime}\right)$ did not significantly effeci concuctor pack hoop stress.

2. Increast ig gap size tends to increase the amount of electromagnetic load carried in hoop tension by conductors on the inside of the major ralius (i.e., conductors 2,4 , and 6 of Figure 4.3) and decrease the amount of electromagnetic load carried by conductors on the outside of the major radius (i.e., conductors 1,3 , and 5 of Figure 4.3). 


\section{RECOMMENDATIONS}

Although this study has shown that conductor hoop stresses are not particularly sensitive to the analysis case winding gaps $\left(0,005\right.$ and $\left.0,010^{\prime \prime}\right)$, it is recommended that these gaps be kept minimal curing the winding process. This recommendation is based upon an understanding of the limitations of this analysis and upon an appreciation of the consequences of conductor pack movement.

It is also recommended that for future analysis of this type consideration be given to existing finite element computer codes that can more accurately analyze this type of problem. For example, the General Dynamics Energy Systems group recently completed a similar analysis for the toroidal field coils using the ANSYS Finite Element Computer Code (see Ref. 6). In that analysis, ANSYS standard library gap elements were used with success. However, this type of analysis is relatively expensive as compared to typical linear elastic analyses and the need for this type of analysis should reflect this increased cost factor. 


\title{
REFERENCES
}

1. Structural Analysis of the Magnet System for Mirror Fusion Test Facility (MFTF), GDC Report No. CASD-LLL-78-003, by J.W. Wohlwend, et al, October 1978.

2. MFTF Conductor Bundle Compaction Tests, LLL memo MF-TR-1.1.2.6, to distribution from John Horvath, dated January 25, 1979.

3. MFTF Structural Analysis Tasks 1 and 2, GD/C memo MFTF-7100-M-112, to R. W. Baldi from C. D. Poniktara, dated December 12, 1978.

4. MFTF Follow-on Activity Coordination Meeting beld at GD/C on 14 December 1978, GD/C memo MFTF-7000-M-113, to distribution from Bob Baldi, dated December 15, 1978.

5. Review of Conductor Force and Joint Strength Requirement, LLL memo MF-TR1.1.2.6.2, to distribution from Ronald Hint2, dated November $29,1978$.

6. Structural Analysis Methods for Laxge Supercondueting Colls, GD/C Report No. CASD-ERR-78-028, by R. W. Baldi, et al, December 1978.

NOTICE

\begin{abstract}
"Work performat under the auspices of the U.S. Deparment of Energy by the Lawrence Livermore Laboratory L'. Her contract number W7405-ENG-48,"

"This report was prepared as an account of work sponsored by the Unitod States Govemment. Neitrer the United States nor the United States Department of Energy, nor any of their employees, not any of their contractors, subconifactors, or their enployets, makes any warranty, express or implied, or assumes any legal liability or responsibility for the accuracy, completeness or usefulsess of any information, apparatus, product or process disclosed, or represents that its use woild not infringe privately-owned rights."
\end{abstract}

Relerence 10 a campany or product name does not imply approval of recommendation of the product by the University of Californis or the U.S. Department of Energy to the exclusion of Others that may be suitable. 